\title{
Does econometric methodology matter to rank universities? An analysis of Italian higher education system
}

\author{
Cristian Barra ${ }^{a}$, Raffaele Lagravinese ${ }^{\mathrm{b}}$, Roberto Zotti ${ }^{\text {a, * }}$ \\ a Department of Economics and Statistics, University of Salerno, Via Giovanni Paolo II, 132, 84084, Fisciano (SA), Italy \\ ${ }^{\mathrm{b}}$ Department of Economics and Mathematical Methods, University of Bari “Aldo Moro”, Piazza Umberto I, 70121, Bari (BA), Italy
}

\section{A R T I C L E I N F O}

\section{Article history:}

Received 11 February 2017

Received in revised form

31 August 2017

Accepted 5 September 2017

Available online 9 September 2017

\section{JEL codes:}

I21

I23

C14

C67

\section{Keywords:}

University league tables

Efficiency

Data Envelopment Analysis

Stochastic Frontier Analysis

\begin{abstract}
A B S T R A C T
In recent years more and more numerous are the rankings published in newspapers or technical reports available, covering many aspects of higher education, but in many cases with very conflicting results between them, due to the fact that universities' performances depend on the set of variables considered and on the methods of analysis employed. This study measures the efficiency of Italian higher education using both parametric and non-parametric techniques and uses the results to provide guidance to university managers and policymakers regarding the most appropriate method for their needs. The findings reveal that, on average and among the macro-areas of the country, the level of efficiency does not change significantly among estimation approaches, which produce different rankings, instead. This may have important implications as rankings have a strong impact on academic decision-making and behaviour, on the structure of the institutions and also on students and graduates recruiters.
\end{abstract}

(๑) 2017 Elsevier Ltd. All rights reserved.

\section{Introduction}

The public budget constraints, due to recent economic crises, and the new funding mechanism of the university system (see Ref. [1] for a description of university governance in Italy), have brought back to the center of Italian academic and political debates the assessment of universities' performances. The analysis of efficiency may not be seen as the only relevant strategic issue; however, from the economic point of view it is one of the most important topics, especially in the recent period, characterized by financial constraint, growing cost pressures, and enhanced competition in the higher educational system [2].

The Italian higher education system has been reformed in last years to join the Bologna Process and universities have started being financed according to their level of virtuosity, in order to achieve higher research performances and to promote academic excellence; "formulas to allocate public funds to higher education

\footnotetext{
* Corresponding author.

E-mail addresses: cbarra@unisa.it (C. Barra), raffaele.lagravinese@uniba.it (R. Lagravinese), rzotti@unisa.it (R. Zotti).
}

institutions are now related to performance indicators such as graduation or completion rates" and "research funding has also increasingly been allocated to specific projects through competitive processes rather than block grants" [3]. The allocation of the resources from the government has been grounded, therefore, on a formula-based mechanism and both quantitative and qualitative indicators were developed to accurately evaluate the management of universities, their productivity in research and teaching and the overall success of their administration; as a consequence, (public) funds to higher education institutions (HEIs) are now related to performance indices according to which evaluate their management and productivity. Therefore, in recent years, measuring how well universities perform has become extremely popular and the subject of increased attention.

The statistical and econometric procedures normally used to assess the efficiency in higher education can be classified into two broad classes: parametric, such as the Stochastic Frontier Approach - hereafter SFA, and non-parametric, such as Data Development Analysis - hereafter DEA (see the seminal papers by Refs. [4] and [5]; respectively). So far, there is no general consensus about which one has to be adopted, as these two main approaches have not only 
different features, but also advantages and disadvantages $[6]^{1}$. The former one may be useful to indicate the significant determinants of educational outcomes; the latter one, instead, can provide information on realistic targets for an inefficient university. More importantly, as Johnes [7] pointed out, "the outcomes from efficiency studies in terms of the rankings of institutions under investigation can vary according to the choice of technique (for example, parametric or non-parametric)"; Chakraborty et al. [8] also underline that before policy actions are being taken, "the stability of the technical efficiency estimates based on the parametric method should be evaluated by comparing them against those determined by the non-parametric method". Therefore, from a political and a managerial standpoint, these diverging results could lead to potentially ineffective decisions. To the best of our knowledge, only few studies have compared DEA to stochastic frontier efficiencies in the higher education context $[9,10]$ even though such comparison has already been applied in the context of school districts [8], local education authorities [11], electricity distribution utilities [12], port industry [13], institutions providing training [14] and using simulations [15,16]. See Johnes [7] for a review and a comparison of the techniques for measuring efficiency. The evidence suggests that the choice of the techniques could affect efficiency scores which wouldn't be an issue in case both methods provide the same ranking but would be, instead, more problematic from a managerial perspective in case no consensus emerge on the group of high and low performing institutions classified. This is not a secondary issue in terms of policy implications as university managers as well as policy makers might choose the estimation approach which is more convenient for them and that best reflects their own preferences (see Ref. [17] on this point).

The first objective of the paper is studying the efficiency of Italian HEIs using data over the four-years from 2008 to 2011, exploiting both parametric and non-parametric methods.

In the non-parametric approach, in order to obtain unbiased coefficients, technical efficiency estimates have been firstly obtained by applying a DEA two-stage with a bootstrap procedure introduced by Simar and Wilson [18]; through which DEA efficiency scores are obtained in the first step and then regressed, in the second step, on potential covariates with the use of a bootstrapped truncated regression. Alternatively, we also apply a socalled double-bootstrap method in which DEA scores are bootstrapped in the first stage to obtain bias corrected efficiency scores, and then a second stage is performed on the basis of the bootstrapped-truncated regression. For an application of such methods in higher education, see Wolszczak-Derlacz and Parteka [19] and Curi et al. [20]. See also Cotte [21] for an application of a two-stage procedure where DEA is performed in the first the stage and a Maximum likelihood estimation is applied in the second step.

Considering the parametric approach, the most recent literature $[22,23]$ emphasized the importance of separating inefficiency and fixed individual effects. Indeed, the efficiency scores may suffer from the presence of incidental parameters (number of fixed-effect parameters) or time-invariant effects, often unobservable, that may distort the estimates. Wang and Ho [23]; in order to incorporate heterogeneity in panel data in the stochastic frontier model, show that first-difference and within transformation can be analytically performed to remove the fixed individual effects, and thus the estimator is immune to the incidental parameters problem (the latter being somehow affecting the methods proposed by Ref. [22]). Moreover, the presence of a multidimensional nature of the production (i.e. multiple outputs) may represent a problem when

\footnotetext{
${ }^{1}$ See Johnes [10] for a description of the parametric and non-parametric approaches' properties.
}

estimating a stochastic production models. To solve this issue, a distance function approach could been considered [24,25]. This technique is particularly useful when no price information, regarding inputs and outputs, is available [26,27] and [10]. Therefore, we employ a Stochastic Frontier Analysis, modelling the production set through an output distance function, using a within transformation to data as developed by Wang and Ho [23].

The second contribution of this study, beyond the analyses on HEIs' performances already performed in the literature, is bringing new evidence on the importance of using the efficiency estimates derived from various estimation methods (i.e. both parametric and non-parametric techniques) to rank universities. Indeed, in recent years, more and more numerous are the rankings published in the newspapers or technical reports available, covering several aspects of higher education, but in many cases with very conflicting results between them (see Ref. [28] for a detailed discussion). This exercise provide guidance to university managers and policymakers, warning them that the estimates of the level of efficiency could vary by estimation techniques and, more importantly, that the ranking of universities may change; this is particularly relevant considering that rankings have a strong impact on academic decision-making and behaviour, and on the structure of the institutions [29], that HEIs are focusing on the criteria with the highest impact on the ranking [30], and that also students and graduates recruiters follow the hierarchy of institutions (see Refs. [31-33]). In other words, as both human and financial resources might depend on how the university is positioned in such classifications, it is useful providing further light on the delicate processes of evaluating the efficiency of HEIs.

Finally, the third goal of the paper is to analyse exogenous factors which potentially affect university (in)efficiency such as some institutional details and characteristics of the market place and of the regions where the universities are located.

The rest of the paper is organized as follows. In Section 2, we present the methodological approaches; Section 3 illustrates the data, production set and model specification for the empirical analysis; Section 4 contains the main results. Finally, Section 5 discusses the managerial and policy implications of the main findings with concluding remarks.

\section{Empirical methodology}

\subsection{Double-bootstrap Data Envelopment Analysis}

Until a few years ago, in the DEA standard technique, Tobitestimator was used to compute the inefficiency analysis in the second step. However, Simar and Wilson [18] have emphasized two possible problems stemming from applying Tobit in this context. First, the results may be biased in the presence of serial correlation between variables at the two stages. Second, the efficiency scores may be biased in finite samples. To obtain unbiased beta coefficients with valid confidence intervals, we follow the doublebootstrap procedure suggested by Simar and Wilson [18]; where DEA scores are bootstrapped in the first stage to achieve bias corrected inefficiency scores and explained in a bootstrapped truncated regression with discretionary explanatory variables. Therefore, in this paper we firstly analyse the technical efficiency using a double-bootstrap DEA method [18]. In particular, we focus on an output-oriented model, following Agasisti and Dal Bianco [34]; who claimed that "as Italian universities are increasingly concerned with reducing the length of studies, and improving the number of graduates, in order to compete for public resources, the output-oriented model appears the most suitable to analyse higher education teaching efficiency". Moreover, output oriented models seem to be particularly appropriate in the context of tertiary 
education according to the fact that the resources used can be considered fixed and that universities cannot influence, at least in the short run, the human, financial and physical capital available [35]. Therefore, we present an output-oriented model. Suppose that a Decision Making Unit (DMU) - in our case the university can be characterized by a technological set $\Psi$ defined as:

$\Psi=\left\{(x, y) \in \Re^{N} \times \Re^{M} \mid x\right.$ can produce $\left.y\right\}$

where $x$ represents a vector of $N$ inputs and $y$ the vector of $M$ outputs.

Specifically, we use a Farrell/Debreu output-oriented technical efficiency measure such as:

$\delta_{j}(x, y)=\max \{\theta:(x, \theta y) \in \Psi\}$

where $\theta$ measures the maximum possible increase in output $\mathrm{y}$, given that inputs $\mathrm{x}$ remain constant.

We assume variable return to scale (VRS); the DEA-VRS is probably the most reliable in our case as suggested by Agasisti [36]; who argued that the assumption of constant return to scale is restrictive because it is reasonable "that the dimension (number of students, amount of resources, etc.) plays a major role in affecting the efficiency" especially if we consider, as we do, the DMUs trying to achieve pre-determinate outputs, given certain inputs.

Thus, at the first stage, we estimate equation (1) through the following linear programming:

$$
\begin{aligned}
\widehat{\delta_{i}} & =\max _{\gamma}\left\{(x, y) \in \Re^{N} \times \Re^{M}: \sum_{i=1}^{n} \gamma_{i} y_{i} \geq y ; \sum_{i=1}^{n} \gamma_{i} y_{i}\right. \\
& \leq x\} \text { such that } \gamma_{i} \geq 0, i=1, \ldots, n
\end{aligned}
$$

where $y$ is a $I \times 1$ vector of constants.

In the second stage, we use the DEA efficiency scores (calculated in the first step) as dependent variable $\left(\widehat{\delta}_{i}\right)$ regressing them on potential exogenous environmental variables $\left(z_{i}\right)$ :

$\widehat{\delta_{i}}=z_{j} \beta+\varepsilon_{j} \quad j=1, \ldots, n$

where $\varepsilon_{j}$ is a statistical noise.

A problem may arise due to the fact that true DEA scores, obtained in the first step, are unobserved and replaced by previously estimates $\widehat{\delta_{i}}$, which, in turn, are serially correlated in an unknown way; moreover, the disturbance error $\varepsilon_{j}$ is correlated with $z_{i}$ as a consequence of the fact that inputs and outputs can be correlated with the environmental variables. To solve these issues, we use a consistent bootstrap approximation of the efficiency distribution, in which DEA scores are bootstrapped in the first stage, to obtain bias corrected efficiency scores; then, in the second stage, in order to analyse the dependency of the efficiency on a set of potential covariates, we apply a consistent bootstrap-truncated regression to consistently estimate the parameters by using maximum likelihood and for inference. We also use a two-stage DEA analysis where the efficiency scores are obtained in the first step and then they are regressed, in the second stage, on potential covariates, using again a bootstrap-truncated regression.

All variables are measures in log-level in order to interpret the estimated coefficients as elasticities. To obtain the DEA efficiency scores, we utilize Wilson's FEAR 1.15 software [37] which is freely available online, and the truncated regression models were then performed in STATA 14 software.

\subsection{A stochastic education distance frontier}

The analysis explores also the Stochastic Frontier Analysis, because it offers useful information on the underlying education production process, as well as information on the extent of inefficiency. Nowadays, the most widely applied SFA technique is the model proposed by Battese and Coelli [38]; to measure technical efficiency across production units. Intuitively, technical efficiency is a measure of the extent to which an institution efficiently allocates the physical inputs at its disposal for a given level of output. The presence of a multidimensional nature of the production (i.e. multiple outputs) may represent a problem when estimating a stochastic production models. To solve this issue a distance function approach has been considered [24,25]. Moreover, this technique is particularly useful when no price information regarding inputs and outputs is available [27]. In line with Abbott and Doucouliagos [39] and Johnes [10]; we choose to model the production set through an output distance function in a panel context. Moreover, on a methodological ground, the most recent literature, which deals with panel data, emphasized the importance of separating inefficiency and fixed individual effects. Indeed, the efficiency scores may suffer from the presence of incidental parameters (number of fixed-effect parameters) or time-invariant effects, often unobservable, that may distort the estimates [22,23]. For instance, students' or researchers' (average) innate abilities may be an important determinant of their individual academic achievements and thus account for a share of the heterogeneity in data when evaluating the efficiency of the institution in which they are studying or working. ${ }^{2}$ As Wang and Ho [23] have underlined: “(...) stochastic frontier models do not distinguish between unobserved individual heterogeneity and inefficiency", forcing "all timeinvariant individual heterogeneity into the estimated inefficiency". In order to deal with this problem and to estimate the technical efficiency, we apply a procedure developed by Wang and Ho [23]; according to whom after transforming the model by either first-difference or within-transformation, the fixed effects are removed before estimation. More specifically, we impose on the data a within transformation; as Wang and Ho [23] specified, "by within-transformation, the sample mean of each panel is subtracted from every observation in the panel. The transformation thus removes the time-invariant individual effect from the model". Following the notation in Wang and Ho [23]; the transformation employed in our model is (being $w$, for instance, any input or output to be transformed):

$w_{i .}=(1 / T) \sum_{t=1}^{T} w_{i t}, w_{i t .}=w_{i t}-w_{i}$

The stacked vector of $w_{i t}$. for a given $\mathrm{i}$ is:

$\tilde{w}_{i .}=\left(w_{i 1 .}, w_{i 2 .}, \ldots, w_{i T .}\right)^{\prime}$

For simplicity, hereafter in our formulation does not include a subscript $\mathrm{t}^{3}$. The baseline model associated to distance function after the transformation can be written as:

\footnotetext{
2 In the context of the use of efficiency models for policy-making, or managerial considerations, the problem of separating the three elements: (i) unobserved structural differences in underlying inputs, (ii) inefficiency and (iii) production process is of crucial importance. Indeed, the lack of judgment about the various parts would lead to a misleading evaluation of estimated inefficiency.

${ }^{3}$ Even though the formulation does not include a subscript $t$, the inefficiency component is time varying in order to examine how the (in)efficiency changes over time.
} 
$f\left(\tilde{y}_{i .}\right)=f\left(\tilde{x}_{1}, \ldots \tilde{x}_{n .}\right)+\tilde{\varepsilon}_{i}$

where $\widetilde{y}$ represent the conventional outputs, $\widetilde{x}$ denote the conventional inputs and $\tilde{\varepsilon}$ denotes the disturbance term. Following a common practice, we now assume a functional form a' la CobbDouglas for the output distance function:

$\ln \tilde{D}_{i .}^{o}=\sum_{m=1}^{M} \tilde{\alpha}_{m} \ln \tilde{y}_{m i .}+\sum_{k=1}^{K} \tilde{\beta}_{k} \ln \tilde{x}_{k i .}+\tilde{v}_{i}$

By a within transformation, $\alpha_{i}$ (intercept that changes over time according to a linear trend with unit-specific time-variation coefficients and that represents time-invariant effects) disappears from our specification. Normalizing by $\tilde{y}_{i}{ }^{4}$, that guarantees the linear homogeneity of degree 1 in outputs $\left(\sum_{m=1}^{M} \tilde{\alpha}_{m}=1\right)$ as suggested by Lovell et al. [25]; the output oriented distance function becomes:

$\ln \left(\frac{\tilde{D}_{i .}^{o}}{\tilde{y}_{i .}}\right)=\sum_{m=1}^{M} \tilde{\alpha}_{m} \ln \tilde{y}_{m i .}^{*}+\sum_{k=1}^{K} \tilde{\beta}_{k} \ln \tilde{x}_{k i .}+\tilde{v}_{i}$

where $\tilde{y}_{m i .}^{*}=\tilde{y}_{m i .} / \tilde{y}_{i .}, \tilde{y}_{n i .}^{*}=\tilde{y}_{n i .} / \tilde{y}_{i .}$ and thus $\widetilde{y_{i .}}=1$. In addition, the time dummies are also taken into account in order to capture exogenous or business cycle effects that can influence the production process of the decision-making units (i.e. universities). It's obvious that $\ln \left(\tilde{D}_{i .}^{o}\right)$ is not observable. Then, in order to solve this problem, we can re-written $\ln \left(\tilde{D}_{i .}^{o} / \tilde{y}_{i .}\right)=\ln \left(\tilde{D}_{i .}^{o}\right)-\ln \left(\tilde{y}_{i}.\right)$. Thus, we transfer $\ln \left(\tilde{D}_{i}^{o}\right)$ to the residuals, i.e. on the right and side of equation (9), and using $-\ln \left(\tilde{y}_{i .}\right)$ as dependent variable [24]. In our case, we follow Paul et al. [40]; i.e. imposing $\ln \left(\tilde{y}_{i}\right)$. equation (9) thus becomes:

$\ln \left(\tilde{y}_{i .}\right)=\sum_{m=1}^{M} \tilde{\alpha}_{m} \ln \left(\tilde{y}_{m i .}^{*}\right)+\sum_{k=1}^{K} \tilde{\beta}_{k} \ln \tilde{x}_{k i .}+\tilde{v}_{i}-\tilde{u}_{i}$

where $\widetilde{u}$ terms stands for inefficiency component, obtained from the truncation to zero of the distribution $N\left(\tilde{m}_{i}, \tilde{\sigma}_{u}^{2}\right)$, where $\tilde{m}_{i}=\tilde{\mu}+\tilde{z}_{i} \tilde{\delta}, \tilde{\mu}$ denoting the location parameter, $\tilde{z}_{i}$ a vector of determinants of (technical) efficiency and $\tilde{\delta}$ is a vector of unknown coefficients; indeed $\tilde{v}$ denotes the vector of random variables assumed to be i.i.d. $N\left(0, \tilde{\sigma}_{v}^{2}\right)$ and independent of the $\tilde{u}$. In other words, the inefficiency of university $i$ is assumed to systematically vary with respect to some determinants (see Section 3 below for more detail on production set). Time dummies are also included in order to capture the influence of exogenous factors. In this analysis, we do not impose the "scaling property" (for more details see Wang and Schmidt [41] and Alvarez et al. [42] because produces estimation problems in our model. In fact, as suggested in literature (see for instance [23]), whether the scaling property holds in the

\footnotetext{
${ }^{4}$ Since they are mathematically equivalent, the choice of the normalizing variable is innocuous when using stochastic frontier models (see Ref. [93]). More importantly, using a similar empirical method to the one we have used in the paper, such as a stochastic output distance frontier, Abbott and Doucouliagos [26] outlined that "It is necessary to impose a number of constraints on the output distance function in order to ensure homogeneity of degree one in outputs, as well as symmetry (see Ref. [92]). This can be achieved by choosing arbitrarily one of the outputs as the normalizing variable; in this paper, research performance is used to serve this role". Therefore, following Abbott and Doucouliagos [26], we decide to normalize by research grants. However, for robustness, we also conduct a sensitivity analysis normalizing by the number of graduates weighted by their degree classification. Results (available on request) are similar.
}

data is ultimately an empirical question. In other words, we assume changes not only in scale but also in the shape of the inefficiency distribution.

With stochastic frontier analysis, a frontier is estimated on the relation between inputs and outputs. This can, for example, be a linear function, a quadratic function or a translog function. However, there is no general consensus about which one has to be adopted in the higher education environment (for a discussion on the different function forms, see Refs. [43] and [44]; see also [45]; where the authors consider both a Translog and a Cobb-Douglas finding that the functional form chosen seems to have a minor impact on main estimates). More specifically, the assumptions behind the use of Cobb-Douglas production functions are plausible in view of the theoretical model which describes the human capital formation in the university system. It allows overcoming the multicollinearity problem associated to estimate a few number of parameters with respect to the Translog function; therefore it is less susceptible to multicollinearity and degrees of freedom problems than the Translog (see Ref. [46]; who uses a Cobb-Douglas function in order to model exogenous variables in human capital formation). ${ }^{5}$ On the other hand, instead, concerning the structure of production possibilities, a more general functional form, that is, the transcendental logarithmic, or "Translog", could be considered for the frontier production function. The Translog functional form may be preferred to the Cobb-Douglas form because of the latter's restrictive elasticity of substitution and scale properties, it allows for non-linear causalities, compared with the more simple CobbDouglas function (see Ref. [47]; who use a Translog function in order to compare the efficiency of public universities among European countries). While the theoretical problem of identifying the correct functional form of HEIs' production processes is discussed in the literature, empirical tests about how different forms affect estimations are quite sparse. The topic itself is important in a managerial perspective; indeed, it is relevant to check whether the judgment about efficiency is affected by the assumptions behind the production process or not. Therefore, this paper uses both a Translog and a Cobb-Douglas production function.

The validity of the heteroschedastic assumption is tested using a Likelihood Ratio (LR) test which allows us to identify the fit of the model and to confirm the imposition of some determinants in the inefficiency term. All coefficients of the output distance function, estimated through a maximum likelihood estimator (MLE), and technical efficiency are obtained using the STATA 12 software.

\section{Data, the production set and model specification}

\subsection{Selected inputs and outputs}

The dataset refers to Italian public universities over the four years period 2008-2011 and it has been constructed using data which are publicly available on the Italian Ministry of Education, Universities and Research (MIUR) Statistical Office website. We exclude all private sector universities, due to the absence of comparable data on academic research; this leaves us with a sample of 53 universities, each of which yields data over the four-year period, so we have a total of 212 observations. The sample is very representative of the higher education system in Italy, corresponding to almost $90 \%$ of the total number of public universities in the country

\footnotetext{
${ }^{5}$ Moreover, in our case the presence of zero values for any inputs or outputs related to the choice of the functional forms does not represent a problem as we do not have any zero values for inputs and outputs; therefore, when we take the log values of both inputs and outputs, there was no need to omit universities with any zero values, thus without implications for the representativeness of the resulting sample.
} 
(we are not able to cover the complete population of universities due to missing information on some of the variables used in the analysis); moreover, the 53 universities included in the empirical analysis cover the $88 \%$ of the students enrolled in the entire higher public education system in Italy.

Referring to the literature on this subject, the production technology is specified, with four inputs: 1 - number of academic staff; 2 percentage of enrolments with a score higher the 9/10 in secondary school; 3 - the percentage of enrolments who attended a lyceum; 4 total number of students. ${ }^{6}$ More specifically, the first input is the number of academic staff (ACAD STAFF $)^{7}$ It is a measure of a human capital input and it aims to capture the human resources used by the universities for teaching activities (see Refs. [10,34]) such as the total academic staff adjusted for the respective academic position (i.e. professors, associate professors, assistant professors and lectures). ${ }^{8}$ The second and third inputs are the percentage of enrolments with a score higher the 9/10 in secondary school (ENR HSG $_{\text {) }}$ and the percentage of enrolments who attended a lyceum ${ }^{9}\left(E R_{\mathrm{LYC}}\right)$, with respect to the total number of students enrolled. Indeed, among the inputs that are commonly known to have effects on students' performances there is the quality of the students on arrival at university. There is strong evidence that the type of secondary high school and preuniversity academic achievement are important determinants of the students' performances [48-51]. The underlying theory is that the ability of students lowers their educational costs and increases their motivation [52]. Thus these two inputs aim to capture the quality of students on arrival at university (i.e. proxies of the knowledge and skills of students when entering tertiary education). ${ }^{10}$ The fourth and last input is the total number of students (STUD) in order to measure the quantity of undergraduates in each university [34].

Moving to the output side, two measures are included in the model reflecting the teaching and research functions of HEIs ${ }^{11}: 1-$ number of graduates weighted by their degree classification; $2-$ research grants. According to Catalano et al. [53] "the task assigned

\footnotetext{
${ }^{6}$ There are no measures of capital inputs (such as library, computing, buildings) which might have a role in determining university outputs; unfortunately such data are very difficult to obtain for Italy. This is confirmed by a recently published paper by De Witte and López-Torres [89] in which they reviewed the literature regarding the efficiency in education. In describing the inputs in the education production function, only a very small amount of paper included those inputs in the analysis in higher education.

7 We have also considered non-academic staff in order to take into account the administrative staff who support the academic staff and the students. As the results (available on request) are similar, we decide to use only the academic staff.

8 We assign weights to each category according to their salary and to the amount of institutional, educational and research duties the academic staff has to deal with (see Refs. $[54,61,90])$ as follows: Academic Staff $\left(\mathrm{ACAD}_{\mathrm{STAFF}}\right)=1$ * professors $+0.75^{*}$ associate professors $+0.50^{*}$ assistant professors $+0.25^{*}$ lectures. A potential limitation of this choice is represented by the decision to assign different weights. Therefore, for robustness, we also further test how alternative weights given to this variable would change the results, to avoid a sever discounting of assistant professors and lectures. In all cases results (available on request) are similar.

${ }^{9}$ For the readers who are not familiar with the characteristics of the Italian secondary school system, in Italy, students before entering at University attend five years of high school. Lyceum is a non-vocational secondary school being more academic oriented and specialized in providing students the skills needed in order to enroll in the university.

${ }^{10}$ We look at the correlation between ENR $_{\mathrm{HSG}}$ and $\mathrm{ENR}_{\mathrm{LYC}}$. Both Pearson and Spearman correlation coefficients are positive and statistically significant, but their magnitude does not suggest to have concerns regarding multicollinearity problems. In other words, we believe these variables control for two different aspects of preenrollment characteristics such as the quality of the secondary school attended (secondary school track chosen) and the secondary high school grade (a measure of academic preparedness). Correlation coefficients are not presented in the paper due to space constraints and available on request.

11 Unfortunately, due to the unavailability of data, we are not able to consider what is known to be the third function of the universities such as knowledge
} transfer to industry and links of HEIs with industrial and business surroundings. to universities is to produce graduates with the utilization and the combination of different resources" and Madden et al. [54] used the number of graduates under the hypothesis that the higher is the number of graduates the higher is the quality of teaching. Also Worthington and Lee [55] considered the number of undergraduate degrees awarded an obvious measure of output for any university; similarly, Eckles [56] used the graduation rate. Thus, the first output included in the analysis is the number of graduates weighted by their degree classification ${ }^{12}$ (GRAD MARKS $_{\text {), in order to capture both }}$ the quantity and the quality of teaching (see also [54,57,58]. As the focus of the paper is on both teaching and research, we include as an output also a measure of research performances of the universities. Academic research is the most controversial output and different proxies have been used in the literature such as bibliometric indicators and peer review [59], weighted indexes of publications and number of research articles [60-65]. Information on the number of publications is not available to us, thus we use research grants (RES) as a second output and as a proxy of research outputs (see Refs. [39,55,66-69]). We follow Agasisti and Johnes [67]; who underlined that "Grants represent a measure of the market value of research done, and so provides a neat conflation of the quantity and quality of research effort. They also provide a measure of research output that is less retrospective than bibliometric analyses". Research grants reflect the market value of the research conducted and can, therefore, be considered as a proxy for output $[70,71]$. Specifically, in our case, it represents the sum of research grants provided by the Italian Ministry of Education (MIUR) for basic research (the so called PRIN projects) and the other amounts provided by MIUR and other Ministries for basic and applied research. The criteria for allocating the grants is based on the quality of research proposals, and to the track record of past results obtained by research groups' proponents. Also, the distribution of research funds obtained in the different years allows considering the multi-year nature of research activities at institution level, in which different research groups obtain grants in different years. It is important to recall that our measure does not represent the final research's final output anyway, as it would be better represented by the final step of activities conducted, such as the academic publications, reports, patents, etc. - in this perspective, grants are much more surely an output, but an intermediate one. We are aware that the use of grant income might raise some problems related to the presence of a lag between the publication of research output and the generation of that research; however, according to Hashimoto and Haneda [72] this is more important when using citation counts or number of patents than research income measure. Moreover, according to Johnes [10]; the use of research grants as an output "is also an attractive measure of research in that it provides an up-to-date picture of research activity and output in the current academic year".13 Thus, also considering that there are no clear criteria for deciding on the appropriate length of lag [73] and following Johnes [10]; we use a static model in our analysis.

\footnotetext{
12 In Italy students can graduate obtaining marks from 66 to 110 with distinction. In order to weight the graduates according to their degree marks, we apply the following procedure: GRAD ${ }_{\text {MARKS }}=1^{*}$ graduates with marks between 106 and 110 with distinction $+0.75^{*}$ graduates with marks between 101 and $105+0.5^{*}$ graduates with marks between 91 and $100+0.25^{*}$ graduates with marks between 66 and 90 The weights have been chosen so that the distance between two ranks is $1 / 4=0.25$. For robustness, we also further test how alternative weights given to

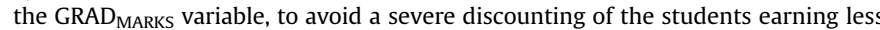
than top marks, would change the results; we've also used just the number of graduates without weighting by their degree classification. In all cases results (available on request) are similar.

${ }^{13}$ See also Frey and Rost [91] for a discussion on the appropriate measures of research quality and quantity.
} 
Table 1

Definition of the variables and descriptive statistics - Mean values by geographical areas.

\begin{tabular}{|c|c|c|c|c|c|}
\hline & & \multicolumn{4}{|l|}{ Mean values } \\
\hline & & North-Western & North-Eastern & Central & Southern \\
\hline \multicolumn{6}{|l|}{ Inputs } \\
\hline ACAD $_{\text {STAFF }^{a}}$ & \# of academic staff (university level) & $1043.56(648.21)$ & $1061.50(832.26)$ & $1221.82(893.12)$ & $797.75(641.73)$ \\
\hline $\mathrm{ENR}_{\mathrm{HSG}}{ }^{\mathrm{b}}$ & $\begin{array}{l}\% \text { of enrolments with a score higher than } 9 / 10 \text { in secondary } \\
\text { school (university level) }\end{array}$ & $3.29(0.96)$ & $3.41(0.70)$ & $3.54(1.05)$ & $3.48(1.05)$ \\
\hline $\mathrm{ENR}_{\mathrm{LYC}}{ }^{\mathrm{b}}$ & $\%$ of enrolments who attended a lyceum & $8.68(1.68)$ & $7.92(206)$ & $8.37(2.15)$ & $7.78(1.41)$ \\
\hline STUD & Total number of students (university level) & $29147.55(18022.32)$ & $28583.58(22975.21)$ & $37425.35(32750.00)$ & $26882.18(20765.05)$ \\
\hline \multicolumn{6}{|c|}{ - } \\
\hline GRAD $_{\text {MARKS }}$ & $\begin{array}{l}\text { \# of graduates weighted by their degree classification } \\
\text { (university level) }\end{array}$ & $3082.15(1951.83)$ & $3241.96(2649.28)$ & $4225.42(3634.122)$ & $2435.71(1962.20)$ \\
\hline RES & Research grants (university level) & $1.17 e+07(7729784)$ & $1.09 e+07(9783430)$ & $1.25 \mathrm{e}+07(9960390)$ & $5808383(5449196)$ \\
\hline \multicolumn{6}{|c|}{ Explaining the inefficiency } \\
\hline MED & Medical School & $0.727(0.450)$ & $0.800(0.405)$ & $0.675(0.474)$ & $0.590(0.494)$ \\
\hline FPS & Fees per student (regional level) & $1157.13(248.55)$ & $1202.83(224.98)$ & $843.95(205.94)$ & $588.47(130.36)$ \\
\hline MK & Market share (university level) & $0.272(0.297)$ & $0.300(0.200)$ & $0.400(0.343)$ & $0.363(0.290)$ \\
\hline YEAR_FOND & Year of foundation & $1803.18(246.41)$ & $1602.30(1657.02)$ & $1657.02(342.32)$ & $1845(215.90)$ \\
\hline WOMEN & \# of females among students & $15655.66(11505.99)$ & $16317.90(12888.19)$ & $21310.80(19645.51)$ & $16078.85(12623.57)$ \\
\hline GDP & Gross domestic product (regional level) & $28.62(2.43)$ & $27.30(1.04)$ & $25.40(1.76)$ & $15.83(1.57)$ \\
\hline FD_1 & Financial Development (1) & $165.86(58.24)$ & $99.87(9.43)$ & $114.48(12.81)$ & $24.04(10.54)$ \\
\hline FD_2 & Financial Development (2) & $71.00(12.29)$ & $54.83(5.10)$ & $65.54(18.42)$ & $19.20(8.64)$ \\
\hline
\end{tabular}

Note: Authors calculation on data collected by the Italian Ministry of Education, Universities and Research Statistical Office.

a In order to get an easy and comprehensible measure, the total number of academic staff is reported in the descriptive statistics. In the analysis, the total number of academic staff has been, instead, adjusted for their respective academic position (i.e. professors, associate professors, assistant professors and lectures).

b Both $\mathrm{ENR}_{\mathrm{HSG}}$ and $\mathrm{ENR}_{\mathrm{LYC}}$ are percentages of the total number of students enrolled.

When looking at the descriptive statistics (Table 1 below), it is interesting to notice that, considering the four geographical areas in which we have aggregated the universities and taking into account the inputs, the Southern area shows the lowest number of academic staff and, interestingly, the highest percentage of enrollments with a score higher than $9 / 10$ in secondary school. The number of students is, instead, more stable across the areas. Considering the performances (output side) by geographical areas, the North-Central areas outperform the Southern area both considering the number of graduates weighted by their degree marks and the grants received for the research activities.

\subsection{Factors affecting university (in)efficiency}

At this stage, DEA and SFA scores are linked with several factors, related to the institutional details and some characteristics of the marketplace and the environment where the institutions are located, that may influence universities' performances. These factors are modelled as variables, which directly influence the variability of the inefficiency term. In other words, they affect the efficiency with which inputs are converted into outputs. The model to be estimated takes on the following form:

$$
\begin{aligned}
\delta_{i, j, t}= & \alpha+\beta_{1} \text { MED }_{i, j, t}+\beta_{2} \text { FPS }_{i, j, t}+\beta_{3} M K_{i, j, t}+\beta_{4} M K_{i, t}^{2} \\
& +\beta_{5} \text { YEAR_FOND }_{i, j, t}+\beta_{6} \text { WOMEN }_{i, j, t}+\beta_{7} G D P_{j, t} \\
& +\beta_{8} \text { FD }_{j, t}+u_{i, j, t}
\end{aligned}
$$

where $i$ refers to single university, $j$ the region where it is located and $t$ denotes time period; MED is a dummy variable equalling 1 if the university has a Medical Faculty and 0 otherwise; it has been included in order to take into account the specificity of faculty composition (see Ref. [74]); for a similar approach); FPS represents the fees per student calculated as the ratio of the amount of income received by the university from the fees paid by the students over the total number of students, in order to take into account the services offered by the institution (the association between efficiency and fees of Italian universities has already taken into account by Refs. [75] and [45] as well as the relationship between fees and level of enrolment by Ref. [76]; $M K$ is the market share measured as the ratio between the number of enrolments at university $i$ and the total number of enrolments in the universities located in the same region, included for capturing the potential effects due to the presence of more concentration or competition between universities; indeed, the market structure of the HEIs could play an important role in calculating the efficiency, as an increase in competition in the higher education sector could lead to greater efficiency (see Refs. $[45,77,78]$ for a discussion); YEAR_FOND is the year of foundation of the university as a proxy for the level of tradition of a given HEIs as, according to [19]; it is often perceived that HEIs with a longer tradition have a better reputation, but it could also be the case that younger HEIs have more flexible and modern structures, assuring a more efficient performance; WOMEN is the number of females among students in order to test the relation between the gender composition of the students and universities' efficiency scores; GDP is the gross domestic product corresponding to the total production of economic goods and services, with the aim of controlling for the growth of the economic system, as the university location can be an important determinant of its performance (the idea that rich and poor areas offer different surroundings has been already explored, with alternate results, by Ref. [79] for secondary schools and [74,80]; and [19]; for higher education); FD represents the financial development measured as aggregate private credits relative to GDP (as robustness we also use aggregate private deposits relative to GDP); finally, $u$ is the vector of error terms. We measure MED, FPS, MK, YEAR_FOND and WOMEN at university level, while GDP and $F D$ are instead measured at regional level. Time dummies have been included with the aim of capturing the inefficiency changes over time. See Table 2 below, for more details on the specification of inputs, outputs and exogenous factors.

\section{Results}

\subsection{Efficiency scores}

Table 3, below, presents the estimated parameters from the DEA 
Table 2

Specification of inputs, outputs and exogenous factors.

\begin{tabular}{ll}
\hline Inputs & ACAD $_{\mathrm{STAFF}} ; \mathrm{ENR}_{\mathrm{HSG}} ; \mathrm{ENR}_{\mathrm{LYC}} ; \mathrm{STU}$ \\
Outputs & $\mathrm{GRAD}_{\mathrm{MARKS}} ; \mathrm{RES}$ \\
Explaining the inefficiency & MED; FPS; MK; YEAR_FOUND; WOMEN; GDP; FD_1; FD_2 \\
\hline
\end{tabular}

ACAD ${ }_{\text {STAFF: }}$ \# of academic staff.

ENR $_{\text {HSG }}$ \% of enrolments with a score higher than $9 / 10$ in secondary school.

ENR $_{\mathrm{LYC}}$ : \% of enrolments who attended a lyceum.

STU: Total number of students.

GRAD MARKS: \# of graduates weighted by their degree classification.

RES: Research grants.

MED: Medical School.

FPS: Fees per student

MK: Market share.

YEAR_FOND: Year of foundation.

WOMEN:\# of females among students.

GDP: Gross domestic product.

FD_1: Financial Development (aggregate private credits/GDP).

FD_2: Financial Development (aggregate private deposits/GDP).

Table 3

Two-stage bootstrap DEA technical efficiency over the period 2008-2011 by geographical areas.

\begin{tabular}{|c|c|c|c|c|c|c|c|c|c|c|c|c|c|c|c|}
\hline & \multicolumn{3}{|l|}{2008} & \multicolumn{3}{|l|}{2009} & \multicolumn{3}{|l|}{2010} & \multicolumn{3}{|l|}{2011} & \multicolumn{3}{|l|}{ Tot } \\
\hline & (a) & (b) & (c) & (d) & (e) & (f) & (g) & (h) & (i) & (l) & $(\mathrm{m})$ & (n) & (o) & (p) & (q) \\
\hline & No boot & Boot & Bias & No boot & Boot & Bias & No boot & Boot & Bias & No boot & Boot & Bias & No boot & Boot & Bias \\
\hline \multicolumn{16}{|c|}{ Geographical areas } \\
\hline North-Western & 0.7575 & 0.6313 & 0.1262 & 0.8026 & 0.6735 & 0.1291 & 0.8547 & 0.7629 & 0.0918 & 0.8732 & 0.7943 & 0.0789 & 0.8220 & 0.7155 & 0.1065 \\
\hline North-Eastern & 0.7221 & 0.5932 & 0.1289 & 0.7936 & 0.6713 & 0.1223 & 0.8777 & 0.7843 & 0.0934 & 0.8906 & 0.8123 & 0.0783 & 0.8210 & 0.7153 & 0.1057 \\
\hline Central & 0.8990 & 0.6713 & 0.2277 & 0.8453 & 0.6733 & 0.1720 & 0.8909 & 0.7728 & 0.1181 & 0.9158 & 0.8112 & 0.1046 & 0.8877 & 0.7322 & 0.1555 \\
\hline Southern & 0.7441 & 0.5958 & 0.1483 & 0.7215 & 0.5987 & 0.1228 & 0.7463 & 0.6571 & 0.0892 & 0.8008 & 0.7178 & 0.0830 & 0.7532 & 0.6423 & 0.1109 \\
\hline
\end{tabular}

Notes:

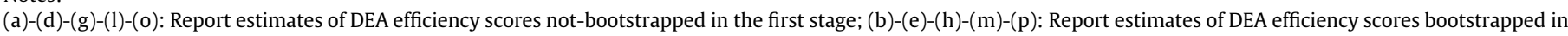
the first stage; (c)-(f)-(i)-(n)-(g): Report Bias refers to the bias found in the estimation.

analysis as described in Section 2.1. The dependent variable is Farrell's bias corrected efficiency score of the i-th university derived from DEA estimates. Table 3 reports both standard efficiencies (No boot - i.e. DEA scores are not bootstrapped) and bias corrected efficiencies (Boot - i.e. DEA scores are bootstrapped) as well as the bias found in our estimation (Bias).

First of all, our evidence suggests the importance of using a double-bootstrapped DEA approach; indeed, the main results are confirmed but a strong bias is found in our estimation, meaning that the efficiency scores calculated without bootstrap might be over-estimated. Examination of Table 3, shows the presence of some geographical effects (by macro-areas) with institutions in the Central-North area (North-Western, North-Eastern and Central) outperforming those in the Southern area; this is customary for the literature on Italian universities (see, e.g., [34]). Taking the average across years into consideration (last three columns of Table 3), the estimated gap of efficiency scores is in the order of slightly less than $10 \%$ between the Central-North regions of the country and the Southern one; for instance the average efficiency of the NorthEastern area is estimated around $72 \%$ - in other words, the output expected can be expanded by around $28 \%$ using the same amount of inputs. Instead, the Southern area is around 64\%, thus their inputs can be used more efficiently for producing around three/fourth more outputs. Tables 4 and 5 below, instead, present the estimated parameters of the stochastic education distance frontier presented in Section 2.2. (both for the Cobb-Douglas and Translog production function); from a methodological perspective, the null hypothesis that there is no heteroscedasticity in the error term has been tested and rejected, at $1 \%$ significance level, using a Likelihood Ratio Test (LR), giving credit to the use of some exogenous variables, according to which the inefficiency term is allowed to change. In other words, the validity of heteroscedastic assumption has been confirmed, leading to the significance of the inefficiency term. The coefficients show that all the inputs variables have a positive and statistically significant effects on the various outcomes of the universities. ${ }^{14}$ The geographical effects (by macro-areas) already found are confirmed with regions in the Central-North area still outperforming those in the Southern area.

Table 6, below, summarizes the efficiency estimates for each university in the sample. When looking at the non-parametric estimates (DEA efficiency scores), the mean efficiency of all universities is 0.6882 (to confirm the importance of obtaining the bootstrapped efficiency scores, the mean efficiency of all universities is 0.8056 without the bootstrapping procedure), with slightly more than $50 \%$ of the universities having a level of efficiency over the sample mean. Again, it is clear than the universities located in the Central-North area perform better than those in the Southern area (75\% of the universities with a level of efficiency over the sample mean are located in the Central-North area). Still taking into account the geographical effects, some information could be gained also when we consider the big city areas where many universities are located. For instance, the Rome area (where Roma La Sapienza, Roma Tor Vergata and Roma Tre are located), is particularly efficient with an average efficiency of 0.7437 among all the years. The Milan area (where Milano University, Milano Bicocca and Milano Politecnico are located) also shows good performances with an average of 0.8090 among all the years. Finally the Naples area (where Napoli Federico II, Napoli II, Napoli L'Orientale and Napoli Parthenope are located), shows lower performances with an average of 0.6465

\footnotetext{
14 LR test coefficients as well as coefficients of inputs and outputs are not showed in the paper due to space constraints, but they are available on request.
} 
Table 4

SFA directional output distance efficiency scores over the period 2008-2011 by geographical areas - Cobb-Douglas production function.

\begin{tabular}{|c|c|c|c|c|c|c|c|c|c|c|c|c|c|c|c|}
\hline & \multicolumn{5}{|c|}{ Model A } & \multicolumn{5}{|c|}{ Model B } & \multicolumn{5}{|c|}{ Model C } \\
\hline & 2008 & 2009 & 2010 & 2011 & Tot & 2008 & 2009 & 2010 & 2011 & Tot & 2008 & 2009 & 2010 & 2011 & Tot \\
\hline \multicolumn{16}{|c|}{ Geographical areas } \\
\hline North-Western & 0.7266 & 0.7102 & 0.7696 & 0.7978 & 0.7511 & 0.8254 & 0.8316 & 0.8666 & 0.8732 & 0.8492 & 0.7201 & 0.7035 & 0.7631 & 0.7923 & 0.7447 \\
\hline North-Eastern & 0.7596 & 0.7384 & 0.8206 & 0.8499 & 0.7906 & 0.8400 & 0.8516 & 0.9050 & 0.9144 & 0.8768 & 0.7514 & 0.7293 & 0.8121 & 0.8419 & 0.7822 \\
\hline Central & 0.8091 & 0.7790 & 0.8303 & 0.8389 & 0.8143 & 0.9060 & 0.9005 & 0.9157 & 0.9158 & 0.9095 & 0.8016 & 0.7705 & 0.8218 & 0.8309 & 0.8062 \\
\hline Southern & 0.5661 & 0.5370 & 0.6054 & 0.6436 & 0.5880 & 0.6472 & 0.6411 & 0.6891 & 0.7095 & 0.6717 & 0.5578 & 0.5287 & 0.5963 & 0.6353 & 0.5795 \\
\hline
\end{tabular}

Notes:

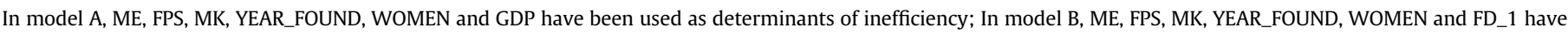
been used as determinants of inefficiency; In model C, ME, FPS, MK, YEAR_FOUND, WOMEN and FD_2 have been used as determinants of inefficiency.

Table 5

SFA directional output distance efficiency scores over the period 2008-2011 by geographical areas - Translog production function.

\begin{tabular}{|c|c|c|c|c|c|c|c|c|c|c|c|c|c|c|c|}
\hline & \multicolumn{5}{|c|}{ Model A } & \multicolumn{5}{|c|}{ Model B } & \multicolumn{5}{|c|}{ Model C } \\
\hline & 2008 & 2009 & 2010 & 2011 & Tot & 2008 & 2009 & 2010 & 2011 & Tot & 2008 & 2009 & 2010 & 2011 & Tot \\
\hline \multicolumn{16}{|c|}{ Geographical areas } \\
\hline North-Western & 0.7824 & 0.8318 & 0.8852 & 0.8876 & 0.8468 & 0.7803 & 0.8303 & 0.8844 & 0.8865 & 0.8454 & 0.7795 & 0.8298 & 0.8855 & 0.8876 & 0.8456 \\
\hline North-Eastern & 0.8083 & 0.8938 & 0.9335 & 0.9480 & 0.8946 & 0.8024 & 0.8895 & 0.9296 & 0.9449 & 0.8902 & 0.7992 & 0.8866 & 0.9281 & 0.9441 & 0.8881 \\
\hline Central & 0.8646 & 0.8867 & 0.9038 & 0.9023 & 0.8894 & 0.8617 & 0.8846 & 0.9016 & 0.9000 & 0.8870 & 0.8614 & 0.8844 & 0.9021 & 0.9018 & 0.8894 \\
\hline Southern & 0.5996 & 0.6446 & 0.6986 & 0.7218 & 0.6662 & 0.5969 & 0.6419 & 0.6956 & 0.7191 & 0.6633 & 0.5968 & 0.6423 & 0.6971 & 0.7208 & 0.6643 \\
\hline
\end{tabular}

Notes:

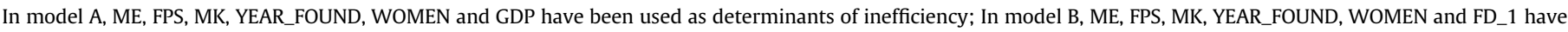
been used as determinants of inefficiency; In model C, ME, FPS, MK, YEAR_FOUND, WOMEN and FD_2 have been used as determinants of inefficiency.

among all the years.

When looking, instead, at the parametric estimates (SFA efficiency scores), it is even more clear than the universities located in the Central-North area perform better than those in the Southern area as now around $86 \%$ of the universities with a level of efficiency over the sample mean are located in the Central-North area (the mean efficiency of all universities is 0.7023 , considering Model A in Table 6), when a Cobb-Douglas production function has been considered. When we consider the big city areas where many universities are located, the Rome area is particularly efficient with an average efficiency of 0.8728 , the Milan area also shows good performances with an average of 0.8713 and the Naples area shows lower performances with an average of 0.6418 among all the years. When instead the Translog production function has been take into account, around $74 \%$ of the universities with a level of efficiency over the sample mean are located in the Central-North area (the mean efficiency of all universities is 0.8043 , considering Model A in Table 6). The Rome area is particularly efficient with an average efficiency of 0.9522 , the Milan area also shows good performances with an average of 0.9466 and the Naples area shows lower performances with an average of 0.7361 among all the years.

The main differences among the two estimation methods employed in the paper regard the university rankings (see Table 7, below). Indeed, looking for instance at the universities ranked in the first 10 position, 8 of them - Università degli Studi "Cà Foscari" Venezia, Università degli Studi di Genova, Università degli Studi di Roma Tre, Università degli Studi Gabriele D'Annunzio - Chieti e Pescara (when using DEA), and - Università degli Studi "La Sapienza" - Roma, Università degli Studi di Firenze, Università degli Studi di Pisa, Università degli Studi "Federico II" - Napoli (when using SFA with a Cobb-Douglas production function), are present only in one of the rankings; instead, only few of them (Politecnico di Milano, Università degli Studi di Padova, Università degli Studi di Bologna, Università degli Studi di Milano, Università degli Studi di Siena, Università degli Studi di Torino) are present in both rankings. Among them, only one of the universities (Università degli Studi di Milano) assumes the same position (6th) confronting DEA and SFA (with a Cobb-Douglas production function). While all the other universities present in both rankings, are positioned differently. Similar findings have also been found at the bottom of the ranking where only 5 institutions are confirmed in last 10 position of the ranking when the two estimation methods are compared. Relevant differences persist when confronting the DEA approach and the SFA when a Translog production function has been assumed when relating inputs and outputs in the stochastic frontier analysis; indeed, still looking at the universities ranked in the first 10 position, 10 of them - Università degli Studi "Cà Foscari" - Venezia, Università degli Studi di Milano, Università degli Studi di Siena, Università degli Studi di Roma Tre, Università degli Studi Gabriele D'Annunzio - Chieti/Pescara (when using DEA), and - Università degli Studi "La Sapienza" - Roma, Università degli Studi di Firenze, Università degli Studi "Federico II" - Napoli, Università degli Studi di Pisa, Università degli Studi di Bari (when using SFA with a Translog production function), are present only in one of the rankings; instead, only few of them (Politecnico di Milano, Università degli Studi di Padova, Università degli Studi di Genova, Università degli Studi di Bologna, Università degli Studi di Torino) are present in both rankings. More similar are, instead, the rankings produced by the two SFA methods (with a Cobb-Douglas and a Translog production function), as 8 out of 10 universities ranked in the first 10 positions are presents in both rankings; among them, two institutions, such as Università degli Studi "La Sapienza" Roma and Università degli Studi di Bologna, assume the same position (1st and 2nd).

These results are furthermore confirmed by the scatter plot in Figs. 1 and 2 below which shows that the different methods do not identify a common set of universities at the top and at the bottom ends of performances, differently from what has been found by Johnes [10] who instead found a common (but very small) group of high and low performing institutions. Similarly to the Johnes [10]; results show that probably the ranking of middle performing universities are less informative.

Boxplots and Kernel distributions of efficiency scores (pooling all years) are presented in Figs. 3 and 4 below. Differences between 
Table 6

DEA technical efficiency and SFA directional output distance efficiency scores over the period 2008-2011 by university.

\begin{tabular}{|c|c|c|c|c|c|c|c|c|c|c|}
\hline & & \multirow{2}{*}{\multicolumn{3}{|c|}{ DEA efficiency scores }} & \multirow{2}{*}{\multicolumn{3}{|c|}{$\frac{\text { SFA efficiency scores }}{\text { Cobb-Douglas }}$}} & \multirow{2}{*}{\multicolumn{3}{|c|}{$\begin{array}{l}\text { SFA efficiency scores } \\
\text { Translog }\end{array}$}} \\
\hline & & & & & & & & & & \\
\hline & & (No boot) & (Boot) & (Bias) & (A) & (B) & (C) & (A) & (B) & (C) \\
\hline 1 & Università Politecnica delle Marche- Ancona & 0.8135 & 0.7548 & 0.0587 & 0.6771 & 0.8014 & 0.6605 & 0.8009 & 0.7946 & 0.7985 \\
\hline 2 & Università della Calabria - Arcavacata di Rende & 0.6642 & 0.6068 & 0.0574 & 0.5872 & 0.6670 & 0.5714 & 0.8152 & 0.8174 & 0.8231 \\
\hline 3 & Politecnico di Bari & 0.6348 & 0.5654 & 0.0694 & 0.4452 & 0.5280 & 0.4395 & 0.4746 & 0.4702 & 0.4718 \\
\hline 4 & Università degli Studi di Bari & 0.8164 & 0.7408 & 0.0756 & 0.7459 & 0.8421 & 0.7342 & 0.9646 & 0.9648 & 0.9654 \\
\hline 5 & Università degli Studi del Sannio - Benevento & 0.6157 & 0.4544 & 0.1613 & 0.4224 & 0.5072 & 0.4139 & 0.4063 & 0.4005 & 0.4007 \\
\hline 6 & Università degli Studi di Bergamo & 1.0000 & 0.7161 & 0.2839 & 0.6033 & 0.7030 & 0.5898 & 0.6916 & 0.6887 & 0.6924 \\
\hline 7 & Università degli Studi di Bologna & 1.0000 & 0.8306 & 0.1694 & 0.9735 & 0.9880 & 0.9718 & 0.9880 & 0.9880 & 0.9887 \\
\hline 8 & Università degli Studi di Brescia & 0.5669 & 0.5226 & 0.0443 & 0.5742 & 0.6741 & 0.5649 & 0.6779 & 0.6751 & 0.6752 \\
\hline 9 & Università degli Studi di Cagliari & 0.7890 & 0.7088 & 0.0802 & 0.6890 & 0.7801 & 0.6825 & 0.8482 & 0.8481 & 0.8476 \\
\hline 10 & Università degli Studi del Molise - Campobasso & 0.8725 & 0.7076 & 0.1649 & 0.5063 & 0.5768 & 0.4998 & 0.5881 & 0.5825 & 0.5812 \\
\hline 11 & Università degli Studi di Cassino & 0.7834 & 0.6092 & 0.1742 & 0.5378 & 0.6680 & 0.5226 & 0.6047 & 0.5996 & 0.5983 \\
\hline 12 & Università degli studi di Catania & 0.7980 & 0.7080 & 0.0900 & 0.7461 & 0.8467 & 0.7325 & 0.9535 & 0.9543 & 0.9555 \\
\hline 13 & Università degli Studi “Magna Grecia” - Catanzaro & 0.8080 & 0.6973 & 0.1107 & 0.4988 & 0.5612 & 0.4897 & 0.5385 & 0.5344 & 0.5374 \\
\hline 14 & Università degli Studi Gabriele D'Annunzio - Chieti/Pescara & 0.9097 & 0.7727 & 0.1370 & 0.6729 & 0.7574 & 0.6670 & 0.9077 & 0.9086 & 0.9097 \\
\hline 15 & Università degli Studi di Ferrara & 0.6677 & 0.6149 & 0.0528 & 0.6623 & 0.7534 & 0.6531 & 0.8214 & 0.8146 & 0.8108 \\
\hline 16 & Università degli Studi di Firenze & 1.0000 & 0.7585 & 0.2415 & 0.9577 & 0.9876 & 0.9527 & 0.9807 & 0.9805 & 0.9809 \\
\hline 17 & Università degli Studi di Foggia & 0.6259 & 0.5760 & 0.0499 & 0.4862 & 0.5361 & 0.4797 & 0.5252 & 0.5204 & 0.5212 \\
\hline 18 & Università degli Studi di Genova & 0.9286 & 0.8375 & 0.0911 & 0.8480 & 0.9453 & 0.8519 & 0.9643 & 0.9626 & 0.9609 \\
\hline 19 & Università del Salento - Lecce & 0.8436 & 0.7703 & 0.0733 & 0.6417 & 0.6777 & 0.6313 & 0.8906 & 0.8890 & 0.8904 \\
\hline 20 & Università degli Studi di Messina & 0.6694 & 0.6137 & 0.0557 & 0.6576 & 0.7336 & 0.6459 & 0.7886 & 0.7899 & 0.7908 \\
\hline 21 & Politecnico di Milano & 0.9544 & 0.8850 & 0.0694 & 0.9172 & 0.9905 & 0.9134 & 0.9678 & 0.9682 & 0.9686 \\
\hline 22 & Università degli Studi di Milano & 0.9575 & 0.8129 & 0.1446 & 0.9408 & 0.9921 & 0.9363 & 0.9633 & 0.9635 & 0.9640 \\
\hline 23 & Università degli Studi - Milano-Bicocca & 0.8112 & 0.7291 & 0.0821 & 0.7559 & 0.9845 & 0.7503 & 0.9087 & 0.9092 & 0.9104 \\
\hline 24 & Università degli Studi di Modena e Reggio Emilia & 0.6802 & 0.6164 & 0.0638 & 0.7053 & 0.8300 & 0.6941 & 0.7896 & 0.7836 & 0.7799 \\
\hline 25 & Seconda Università degli studi di Napoli & 0.6210 & 0.5707 & 0.0503 & 0.6090 & 0.7286 & 0.6066 & 0.7571 & 0.7550 & 0.7542 \\
\hline 26 & Università degli Studi “Federico II" - Napoli & 0.8058 & 0.7035 & 0.1023 & 0.8700 & 0.9657 & 0.8636 & 0.9671 & 0.9670 & 0.9670 \\
\hline 27 & Università degli Studi “L' Orientale” - Napoli & 0.9837 & 0.7639 & 0.2198 & 0.6292 & 0.7271 & 0.6251 & 0.7161 & 0.7107 & 0.7124 \\
\hline 28 & Università degli Studi “Parthenope" - Napoli & 0.6246 & 0.5479 & 0.0767 & 0.4593 & 0.5877 & 0.4553 & 0.5044 & 0.5031 & 0.5022 \\
\hline 29 & Università degli Studi di Padova & 0.9380 & 0.8504 & 0.0876 & 0.9481 & 0.9788 & 0.9413 & 0.9783 & 0.9783 & 0.9783 \\
\hline 30 & Università degli Studi - Palermo & 0.8431 & 0.7391 & 0.1040 & 0.7584 & 0.8363 & 0.7480 & 0.9589 & 0.9587 & 0.9605 \\
\hline 31 & Università degli Studi di Parma & 0.7091 & 0.6557 & 0.0534 & 0.7563 & 0.8733 & 0.7454 & 0.9124 & 0.9093 & 0.9065 \\
\hline 32 & Università degli Studi di Pavia & 0.8219 & 0.7440 & 0.0779 & 0.7882 & 0.8646 & 0.7787 & 0.8983 & 0.8981 & 0.8983 \\
\hline 33 & Università degli Studi di Perugia & 0.7972 & 0.7358 & 0.0614 & 0.8151 & 0.9376 & 0.8030 & 0.9224 & 0.9192 & 0.9215 \\
\hline 34 & Università degli Studi di Pisa & 0.8051 & 0.7219 & 0.0832 & 0.8841 & 0.9677 & 0.8651 & 0.9664 & 0.9661 & 0.9670 \\
\hline 35 & Università degli Studi della Basilicata - Potenza & 0.9119 & 0.6522 & 0.2597 & 0.4512 & 0.5213 & 0.4409 & 0.5049 & 0.5006 & 0.4994 \\
\hline 36 & Università degli Studi Mediterranea - Reggio Calabria & 0.5158 & 0.4451 & 0.0707 & 0.4558 & 0.5421 & 0.4453 & 0.4906 & 0.4860 & 0.4874 \\
\hline 37 & Università degli Studi di Roma Tre & 0.8849 & 0.8092 & 0.0757 & 0.8317 & 0.9846 & 0.8329 & 0.9535 & 0.9533 & 0.9528 \\
\hline 38 & Università degli Studi “La Sapienza” - Roma & 1.0000 & 0.6854 & 0.3146 & 0.9827 & 0.9942 & 0.9829 & 0.9899 & 0.9898 & 0.9898 \\
\hline 39 & Università degli Studi di “Tor Vergata” - Roma & 0.7936 & 0.7367 & 0.0569 & 0.8041 & 0.9814 & 0.8100 & 0.9132 & 0.9127 & 0.9114 \\
\hline 40 & Università degli Studi di Salerno & 0.5799 & 0.5302 & 0.0497 & 0.5586 & 0.6503 & 0.5489 & 0.7177 & 0.7158 & 0.7158 \\
\hline 41 & Università degli Studi di Sassari & 0.6374 & 0.5757 & 0.0617 & 0.5819 & 0.6623 & 0.5734 & 0.6209 & 0.6199 & 0.6194 \\
\hline 42 & Università degli Studi di Siena & 1.0000 & 0.8128 & 0.1872 & 0.9430 & 0.9738 & 0.9380 & 0.9498 & 0.9487 & 0.9517 \\
\hline 43 & Università degli Studi di Teramo & 1.0000 & 0.6816 & 0.3184 & 0.4638 & 0.5430 & 0.4552 & 0.5561 & 0.5509 & 0.5530 \\
\hline 44 & Politecnico di Torino & 0.8202 & 0.7294 & 0.0908 & 0.7161 & 0.8562 & 0.7104 & 0.8812 & 0.8806 & 0.8758 \\
\hline 45 & Università degli Studi di Torino & 0.9000 & 0.7823 & 0.1177 & 0.9377 & 0.9809 & 0.9337 & 0.9809 & 0.9808 & 0.9805 \\
\hline 46 & Università degli Studi - Trieste & 0.8302 & 0.7483 & 0.0819 & 0.7739 & 0.8364 & 0.7697 & 0.9225 & 0.9181 & 0.9140 \\
\hline 47 & Università degli Studi - Udine & 0.6904 & 0.6242 & 0.0662 & 0.7134 & 0.8669 & 0.7066 & 0.8319 & 0.8250 & 0.8196 \\
\hline 48 & Università dell' Insubria - Varese & 0.6787 & 0.5866 & 0.0921 & 0.6200 & 0.7247 & 0.6090 & 0.6987 & 0.6950 & 0.6962 \\
\hline 49 & Venezia - Università IUAV & 1.0000 & 0.6733 & 0.3267 & 0.8148 & 0.8878 & 0.8039 & 0.8397 & 0.8289 & 0.8284 \\
\hline 50 & Università degli Studi “Cà Foscari” - Venezia & 0.9321 & 0.8446 & 0.0875 & 0.8106 & 0.8906 & 0.7975 & 0.9490 & 0.9468 & 0.9467 \\
\hline 51 & Università degli Studi del Piemonte orientale “A. Avogadro” & 0.6026 & 0.5250 & 0.0776 & 0.5601 & 0.6252 & 0.5538 & 0.6819 & 0.6777 & 0.6789 \\
\hline 52 & Università degli Studi di Verona & 0.7625 & 0.6946 & 0.0679 & 0.7268 & 0.8513 & 0.7162 & 0.8866 & 0.8833 & 0.8818 \\
\hline 53 & Università della Tuscia - Viterbo & 1.0000 & 0.6974 & 0.3026 & 0.7101 & 0.7988 & 0.6941 & 0.8121 & 0.8052 & 0.8022 \\
\hline
\end{tabular}

Notes:

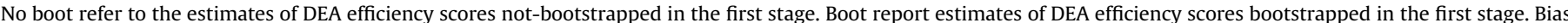
refers to the bias found in the estimation.

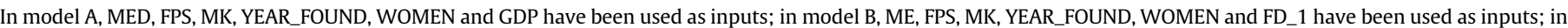
model C, MED, FPS, MK, YEAR_FOUND, WOMEN and FD_2 have been used as inputs.

efficiencies of universities not only in the mean, but also in the distribution is shown through the boxplots; considering the Kernel distributions, the universities are more efficient, the closer they come to the value of one. North-Central regions of the country are characterized by a skewed distribution with more concentration in the direction of more efficient units; moreover, comparing biased (non-bootstrapped) and unbiased (bootstrapped) efficiency scores, it's clear that the distribution of the latter one are slightly on the left indicating lower level of efficiency scores.

\section{2. (In)efficiency score determinants}

When considering the exogenous factors included in the analysis, our findings show that the variables used to control for the different competitive environment in which institutions are located, have an important role in describing the inefficiency term. In both DEA and SFA formulations, a positive sign of the estimated regression parameter indicates that, ceteris paribus, an increase in a variable corresponds to higher inefficiency (lower efficiency), while 
Table 7

DEA and SFA technical efficiency over the period 20082011 by university - Ranking of universities.

\begin{tabular}{|c|c|c|c|c|c|c|c|c|}
\hline N. & Universities & DEA & N. & Universities & $\begin{array}{l}\text { SFA }(A) \\
\text { Cobb Douglas }\end{array}$ & N. & Universities & $\begin{array}{l}\text { SFA (A) } \\
\text { Translog }\end{array}$ \\
\hline 1 & Politecnico di Milano & 0.885 & 1 & Università degli Studi “La Sapienza” - Roma & 0.982 & 1 & Università degli Studi “La Sapienza” - Roma & 0.989 \\
\hline 2 & Università degli Studi di Padova & 0.850 & 2 & Università degli Studi di Bologna & 0.973 & 2 & Università degli Studi di Bologna & 0.988 \\
\hline 3 & Università degli Studi "Cà Foscari” - Venezia & 0.844 & 3 & Università degli Studi di Firenze & 0.957 & 3 & Università degli Studi di Torino & 0.980 \\
\hline 4 & Università degli Studi di Genova & 0.837 & 4 & Università degli Studi di Padova & 0.948 & 4 & Università degli Studi di Firenze & 0.980 \\
\hline 5 & Università degli Studi di Bologna & 0.830 & 5 & Università degli Studi di Siena & 0.943 & 5 & Università degli Studi di Padova & 0.978 \\
\hline 6 & Università degli Studi di Milano & 0.812 & 6 & Università degli Studi di Milano & 0.940 & 6 & Politecnico di Milano & 0.967 \\
\hline 7 & Università degli Studi di Siena & 0.812 & 7 & Università degli Studi di Torino & 0.937 & 7 & Università degli Studi “Federico II" - Napoli & 0.967 \\
\hline 8 & Università degli Studi di Roma Tre & 0.809 & 8 & Politecnico di Milano & 0.917 & 8 & Università degli Studi di Pisa & 0.966 \\
\hline 9 & Università degli Studi di Torino & 0.782 & 9 & Università degli Studi di Pisa & 0.884 & 9 & Università degli Studi di Bari & 0.964 \\
\hline 10 & $\begin{array}{l}\text { Università degli Studi Gabriele D'Annunzio - } \\
\text { Chieti e Pescara }\end{array}$ & 0.772 & 10 & Università degli Studi “Federico II" - Napoli & 0.870 & 10 & Università degli Studi di Genova & 0.964 \\
\hline 11 & Università del Salento - Lecce & 0.770 & 11 & Università degli Studi di Genova & 0.848 & 11 & Università degli Studi di Milano & 0.963 \\
\hline 12 & Università degli Studi “L' Orientale" - Napoli & 0.763 & 12 & Università degli Studi di Roma Tre & 0.831 & 12 & Università degli Studi - Palermo & 0.958 \\
\hline 13 & Università degli Studi di Firenze & 0.758 & 13 & Università degli Studi di Perugia & 0.815 & 13 & Università degli studi di Catania & 0.953 \\
\hline 14 & Università Politecnica delle Marche- Ancona & 0.754 & 14 & Venezia - Università IUAV & 0.814 & 14 & Università degli Studi di Roma Tre & 0.953 \\
\hline 15 & Università degli Studi - Trieste & 0.748 & 15 & Università degli Studi “Cà Foscari” - Venezia & 0.810 & 15 & Università degli Studi di Siena & 0.949 \\
\hline 16 & Università degli Studi di Pavia & 0.744 & 16 & Università degli Studi di "Tor Vergata" - Roma & 0.804 & 16 & Università degli Studi "Cà Foscari” - Venezia & 0.949 \\
\hline 17 & Università degli Studi di Bari & 0.740 & 17 & Università degli Studi di Pavia & 0.788 & 17 & Università degli Studi - Trieste & 0.922 \\
\hline 18 & Università degli Studi - Palermo & 0.739 & 18 & Università degli Studi - Trieste & 0.773 & 18 & Università degli Studi di Perugia & 0.922 \\
\hline 19 & Università degli Studi di “Tor Vergata” - Roma & 0.736 & 19 & Università degli Studi - Palermo & 0.758 & 19 & Università degli Studi di “Tor Vergata” - Roma & 0.913 \\
\hline 20 & Università degli Studi di Perugia & 0.735 & 20 & Università degli Studi di Parma & 0.756 & 20 & Università degli Studi di Parma & 0.912 \\
\hline 21 & Politecnico di Torino & 0.729 & 21 & Università degli Studi - Milano-Bicocca & 0.755 & 21 & Università degli Studi - Milano-Bicocca & 0.908 \\
\hline 22 & Università degli Studi - Milano-Bicocca & 0.729 & 22 & Università degli studi di Catania & 0.746 & 22 & $\begin{array}{l}\text { Università degli Studi Gabriele } \\
\text { D'Annunzio - Chieti/Pescara }\end{array}$ & 0.907 \\
\hline 23 & Università degli Studi di Pisa & 0.721 & 23 & Università degli Studi di Bari & 0.745 & 23 & Università degli Studi di Pavia & 0.898 \\
\hline 24 & Università degli Studi di Bergamo & 0.716 & 24 & Università degli Studi di Verona & 0.726 & 24 & Università del Salento - Lecce & 0.890 \\
\hline 25 & Università degli Studi di Cagliari & 0.708 & 25 & Politecnico di Torino & 0.716 & 25 & Università degli Studi di Verona & 0.886 \\
\hline 26 & Università degli studi di Catania & 0.708 & 26 & Università degli Studi - Udine & 0.713 & 26 & Politecnico di Torino & 0.881 \\
\hline 27 & Università degli Studi del Molise - Campobasso & 0.707 & 27 & Università della Tuscia - Viterbo & 0.710 & 27 & Università degli Studi di Cagliari & 0.848 \\
\hline 28 & Università degli Studi "Federico II" - Napoli & 0.703 & 28 & Università degli Studi di Modena e Reggio Emilia & 0.705 & 28 & Venezia - Università IUAV & 0.839 \\
\hline 29 & Università della Tuscia - Viterbo & 0.697 & 29 & Università degli Studi di Cagliari & 0.689 & 29 & Università degli Studi - Udine & 0.831 \\
\hline 30 & Università degli Studi “Magna Grecia” - Catanzaro & 0.697 & 30 & Università Politecnica delle Marche- Ancona & 0.677 & 30 & Università degli Studi di Ferrara & 0.821 \\
\hline 31 & Università degli Studi di Verona & 0.694 & 31 & $\begin{array}{l}\text { Università degli Studi Gabriele } \\
\text { D'Annunzio - Chieti/Pescara }\end{array}$ & 0.672 & 31 & Università della Calabria - Arcavacata di Rende & 0.815 \\
\hline 32 & Università degli Studi “La Sapienza” - Roma & 0.685 & 32 & Università degli Studi di Ferrara & 0.662 & 32 & Università della Tuscia - Viterbo & 0.812 \\
\hline 33 & Università degli Studi di Teramo & 0.681 & 33 & Università degli Studi di Messina & 0.657 & 33 & Università Politecnica delle Marche- Ancona & 0.800 \\
\hline 34 & Venezia - Università IUAV & 0.673 & 34 & Università del Salento - Lecce & 0.641 & 34 & Università degli Studi di Modena e Reggio Emilia & 0.789 \\
\hline 35 & Università degli Studi di Parma & 0.655 & 35 & Università degli Studi "L' Orientale" - Napoli & 0.629 & 35 & Università degli Studi di Messina & 0.788 \\
\hline 36 & Università degli Studi della Basilicata - Potenza & 0.652 & 36 & Università dell'Insubria - Varese & 0.620 & 36 & Seconda Università degli studi di Napoli & 0.757 \\
\hline 37 & Università degli Studi - Udine & 0.624 & 37 & Seconda Università degli studi di Napoli & 0.609 & 37 & Università degli Studi di Salerno & 0.717 \\
\hline 38 & Università degli Studi di Modena e Reggio Emilia & 0.616 & 38 & Università degli Studi di Bergamo & 0.603 & 38 & Università degli Studi "L' Orientale" - Napoli & 0.716 \\
\hline 39 & Università degli Studi di Ferrara & 0.614 & 39 & Università della Calabria - Arcavacata di Rende & 0.587 & 39 & Università dell'Insubria - Varese & 0.698 \\
\hline 40 & Università degli Studi di Messina & 0.613 & 40 & Università degli Studi di Sassari & 0.581 & 40 & Università degli Studi di Bergamo & 0.691 \\
\hline 41 & Università degli Studi di Cassino & 0.609 & 41 & Università degli Studi di Brescia & 0.574 & 41 & & 0.681 \\
\hline
\end{tabular}

(continued on next page) 
42 Università della Calabria - Arcavacata di Rende

43 Università dell' Insubria - Vares

44 Università degli Studi di Foggia

45 Università degli Studi di Sassari

46 Seconda Università degli studi di Napol

7 Politecnico di Bari

48 Università degli Studi "Parthenope" - Napoli

49 Università degli Studi di Salerno

50 Università degli Studi del Piemonte

orientale "A. Avogadro"

51 Università degli Studi di Brescia

52 Università degli Studi del Sannio - Benevento

53 Università degli Studi Mediterranea - Reggio Calabria

0.60642 Università degli Studi del Piemonte

$$
\text { orientale "A. Avogadro" }
$$

0.58643 Orientale "A. Avogadro"

0.58643 Universita degili Studi di Salerno

0.57545 Università degli Studi di Cassino - Campobasso

0.57046 Università degli Studi “Manna Grecia” - Catanzaro

$0.565 \quad 47$ Università degli Studi di Foggia

$0.547 \quad 48$ Università degli Studi di Teramo

$0.525 \quad 50$ Università degli Studi Mediterranea - Reggio Calabria 0.455

$0.52251 \quad$ Università degli Studi della Basilicata - Potenza

$0.454 \quad 52 \quad$ Politecnico di Bari

0.44553 Università degli Studi del Sannio - Benevento

0.451

0.445

0.422

0.560

Università degli Studi del Piemonte

orientale "A. Avogadro"

$0.558 \quad 43$ Università degli Studi di Sassari $\quad 0.620$

$0.537 \quad 44$ Università degli Studi di Cassino $\quad 0.604$

$0.506 \quad 45$ Università degli Studi del Molise - Campobasso 0.588

$\begin{array}{llll}0.498 & 46 & \text { Università degli Studi di Teramo } & 0.556\end{array}$

47 Università degli Studi "Magna Grecia" - Catanzaro $\quad 0.538$

48 Università degli Studi di Foggia

49 Università degli Studi della Basilicata - Potenza $\quad 0.504$

50 Università degli Studi "Parthenope" - Napoli $\quad 0.504$

51 Università degli Studi Mediterranea - Reggio Calabria 0.490

52 Politecnico di Bari $\quad 0.474$

Notes: DEA: Estimates of DEA efficiency scores bootstrapped in the first stage are reported; SFA: MED, FPS, MK, YEAR_FOUND, WOMEN and GDP have been used as outputs.

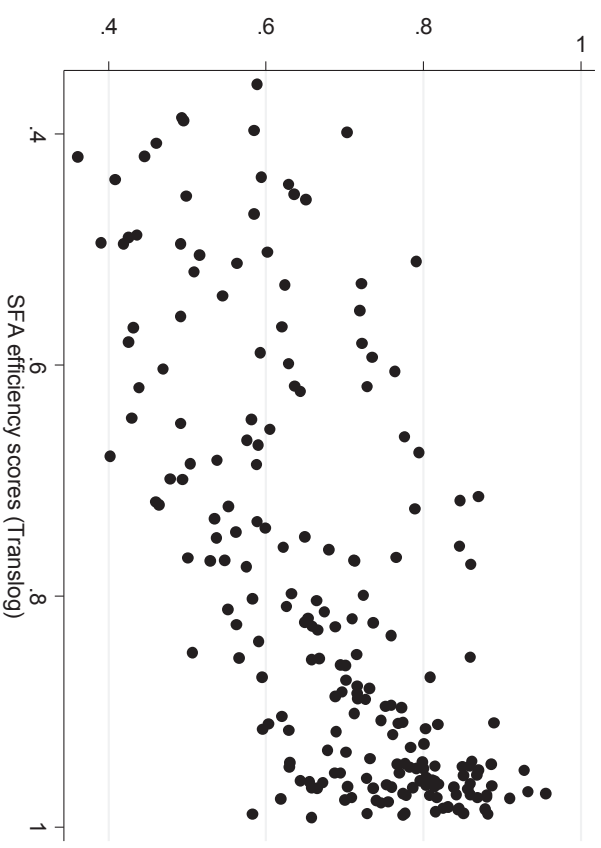

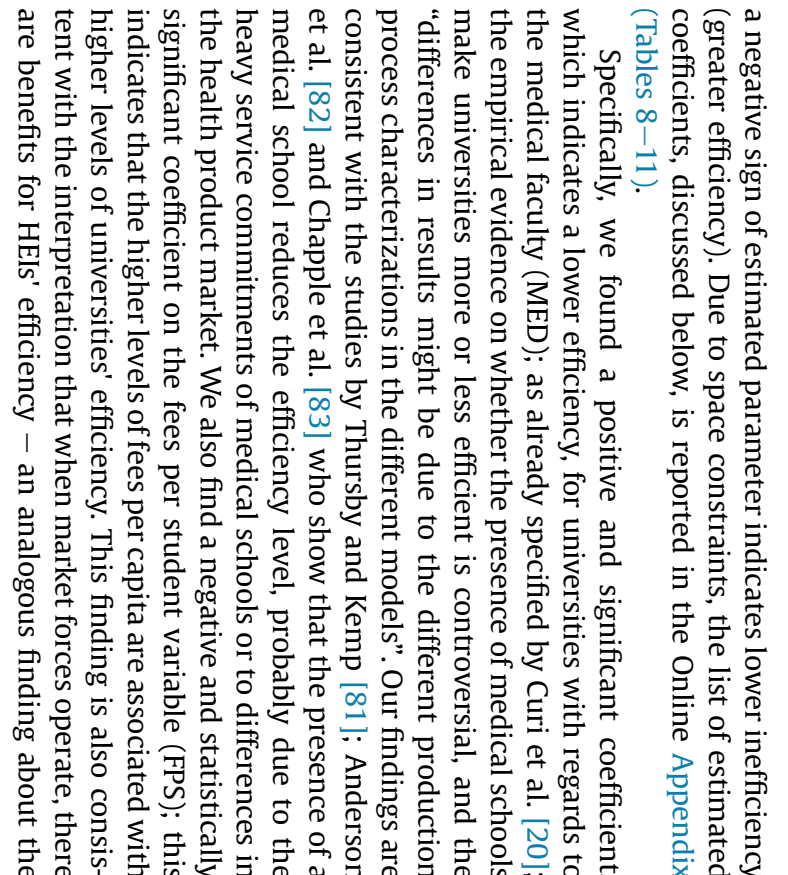

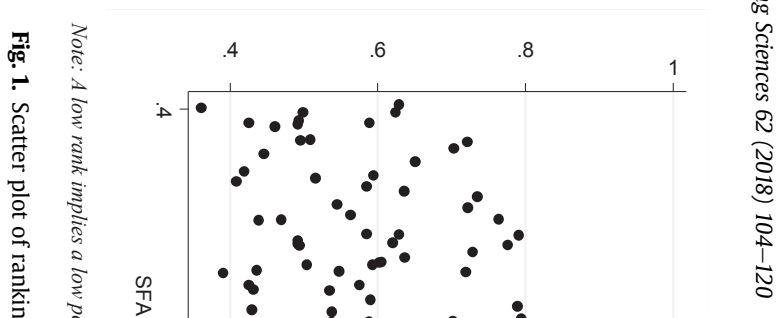


North-Western regions

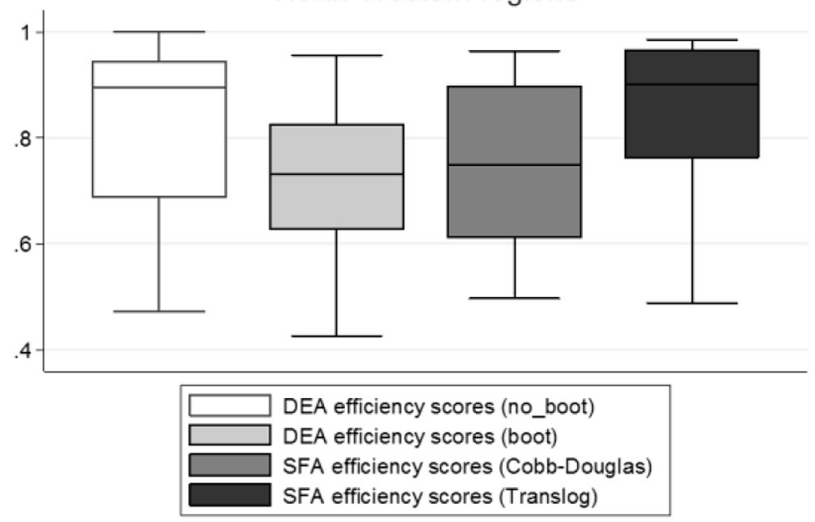

excludes outside values

Central regions

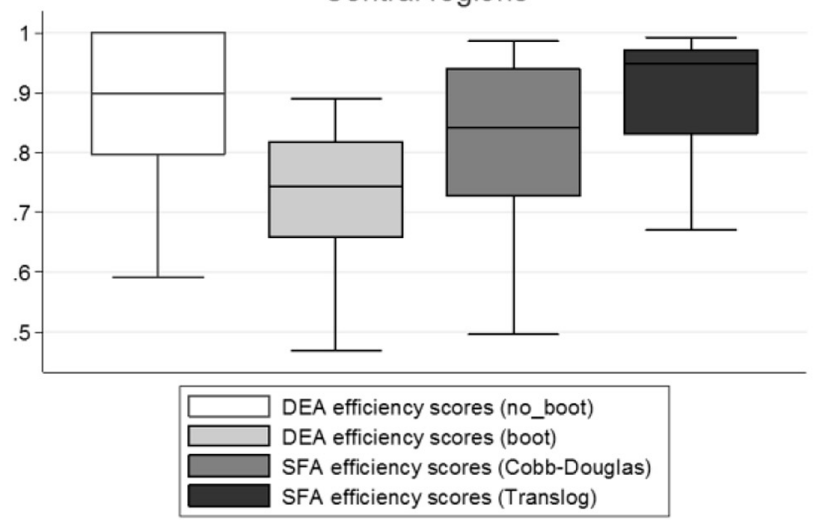

excludes outside values
North-Eastern regions

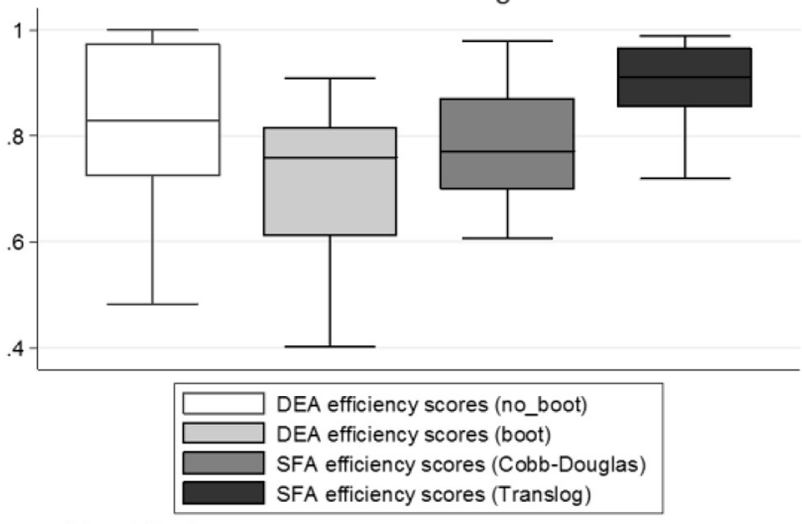

excludes outside values

Southern regions

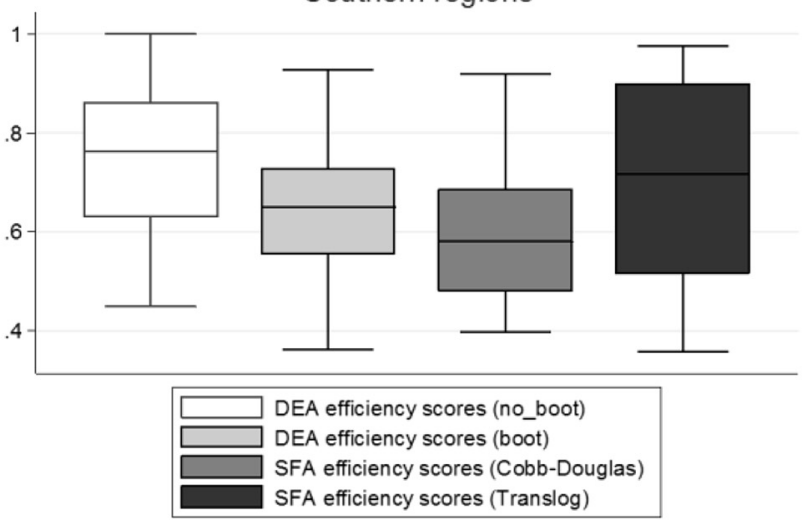

excludes outside values

Fig. 3. Boxplots efficiency scores.
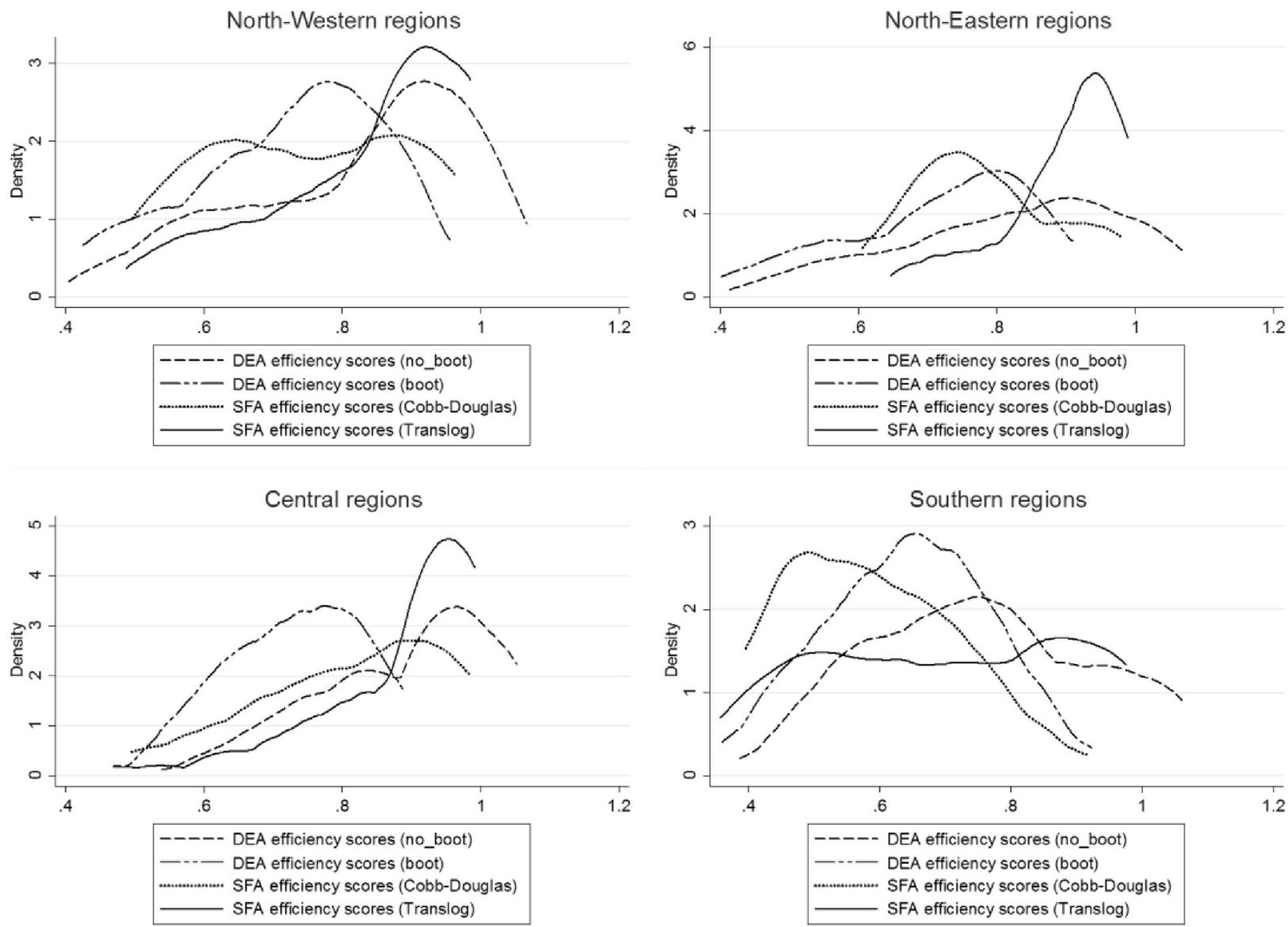

Fig. 4. Kernel density estimates. 
positive association between efficiency and fees of Italian universities is in Agasisti et al. [45] and Agasisti and Wolszczak-Derlacz [84]. Moreover, inefficiency has a U-shaped relationship with respect to the measure of market competition (MK), showing a negative and statistically significant relationship between inefficiency and market share while, instead, a positive and statistically significant relationship between inefficiency and (squared) market share has been found. In other words, the increase in concentration does not lead to a linear change in efficiency; at some point, the effect becomes positive, and the quadratic shape means that the inefficiency of HEIs with respect to the measure of market concentration is increasing as concentration increases (i.e. universities are less efficient), and the results can be due to the finishing incentives in becoming efficient when concentration arises indeed. This is only one of the channel through which the market structure might play a role as our measure of competition is specifically build on the geographical proximity among universities within the region; however, this is an interesting portion of competition effect as Italian students tend to choose a university located in their own region, despite the Italian university system offers different quality standards, due to family income constraint (on this point see Ref. [85]). Overall, these findings suggest that differences in performances might be due to the market structure of higher education, in the direction that a more competitive environment could lead to higher efficiency, consistently with Agasisti et al. [45]; Agasisti [75] and Rossi [86]. The estimation results reveal that the coefficient associated with the presence of female students (WOMEN) is, in general, negative and statistically significant, meaning that the higher is the share of females among the students the higher is the efficiency of the universities. A negative and statistically significant coefficient has been found on the variable gross domestic product (GDP), and on the financial progress variables (FD_1 and FD_2), which means that operating in more economically developed areas is associated, on average, with higher efficiency. Finally, results show that younger universities (YEAR_FOND) are less efficient.

\section{Conclusions}

In this paper we have attempted to analysis the efficiency of Italian higher education using both parametric and non-parametric methods with the aim of providing guidance to university managers and policymakers on the sensitivity of the results to the technique used. To do this, we firstly employ both a doublebootstrap procedure and a two-stage bootstrap Data Envelopment Analysis (DEA), to generate unbiased coefficients [18] and then a Stochastic Frontier Analysis (SFA both with a Cobb-Douglas and a Translog production function), modelling the production set through an output distance function, applying a within transformation to data as developed by Wang and Ho [23]; exogenous factors, such as some institutional details and characteristics of the market place and of the regions where the universities are located, have been also taken into account to evaluate which determinants have an impact on universities' efficiencies.

Firstly, the findings suggest the presence of some geographical effects with institutions located in the Central-North area showing higher efficiency scores than those in the Southern area, with both the empirical approaches. This result is in line with the idea that universities need guidelines to follow in order to avoid waste of public funding; indeed, a debate is emerging about the weakened role of universities in Italy, due to the cut in public funding. Particularly in weak areas, like those of the South of Italy, where the main producer of knowledge is public university, the effect of linking public funding to performance could also produce negative cumulative effects: for example, students may prefer universities in the North of Italy, thus destroying the possibility of local knowledge spillovers $[87,88]$. More specifically, when apply a bootstrapping method in contrast to straightforward application of DEA (in order to investigate the sensibility of efficiency scores relative to the sampling variations of the estimated frontier and thus obtain bias corrected efficiency estimates) the empirical evidence shows that the efficiency scores calculated without bootstrap might be overestimated suggesting the importance of using a bootstrapped DEA approach.

Secondly, results show that, on average, the level of efficiency does not significantly change among estimation methods, but at the same time they produce different rankings (especially when confronting DEA and SFA models). Indeed, looking at the universities ranked in the first 10 positions, most of them are present only in one of the rankings; instead, only few of them are present in both. Moreover, only one of the universities assumes the same position, while all the other universities present in both rankings, are positioned differently. Those differences are confirmed among the low performing universities, implying that the two methods may be able to provide useful information more at the top and bottom of the performances, being instead less informative in the middle, as the evidence shows that they do not identify a common set of high and low performing institutions. Interestingly, different rankings are produced mainly between estimation methods such as DEA versus SFA (both with a Cobb-Douglas and a Translog production function). Assumption on the functional forms are less informative as the league tables produced within the same estimation method (SFA with a Cobb-Douglas and a Translog production function) are, instead, more similar. In other words, the methods of analysis employed do matter when ranking universities, suggesting that university rankings should be handled with extreme caution.

Thirdly, at the second stage of our analysis, we linked the technical efficiency scores of single HEIs with variables describing their location, the institution, year of foundation and some characteristics of the marketplace; interestingly, the results show that inefficiency is U-shaped relationship with respect to the measure of market competition in favor of a more competitive environment in order to reach higher efficiency and that the higher is the level of fees per capita the lower is the universities' inefficiency. All findings that provide a clue towards the expansion of pro-competitive policies in the Italian higher education sector, consistently with the interpretation that when market forces operate, there are benefits for university efficiency, pointing at a development of a quasi-market in the provision of education where students are free to choose the university to attend and institutions are allowed to compete for students.

To conclude, the lesson learned suggests that policymakers should be aware that the estimates of the level of efficiency could vary by estimation methods and, more importantly, that the ranking of universities may change as ineffective decisions might be driven from potential diverging results and in case no consensus emerge on the group of high and low performing institutions rated; indeed, in other words, university managers may be appealed, in order to improve their ranking, attract more students and obtain more funding, to rely on the most appropriate method for their needs and that best reflects their own preferences. As both human and financial resources and decisions might depend on how the universities are positioned in such classifications, it is useful to providing further light on the delicate processes of evaluating the efficiency of HEIs. The lack of empirical evidence in the literature about the proximity of these two approaches in measuring technical efficiency of higher education calls into question the need of providing new evidence regarding the success of efficiency analyses in producing reliable and consistent estimates and, more importantly, rankings of institutions, which are not sensitive to the 
specification of the technique used to produce the efficiency scores.

\section{APPENDIX}

Table 8

DEA truncated bootstrapped second stage regression.

\begin{tabular}{|c|c|c|c|c|c|c|}
\hline \multirow[b]{3}{*}{ Variables } & \multicolumn{3}{|c|}{ Min-Max Truncation - UB $=0.64 \&$ LB $=0.04$} & \multicolumn{3}{|c|}{ Min-Max Truncation - UB $=0.90 \&$ LB $=0.40$} \\
\hline & \multicolumn{3}{|l|}{ BOOT } & \multicolumn{3}{|l|}{ NO-BOOT } \\
\hline & (1) & $(2)$ & (3) & $(4)$ & $(5)$ & (6) \\
\hline MED & $0.058^{* *}(0.023)$ & $0.063^{* * *}(0.015)$ & $0.062^{* * *}(0.017)$ & $0.154^{* * *}(0.029)$ & $0.158^{* * *}(0.028)$ & $0.158^{* * *}(0.031)$ \\
\hline FPS & $-0.0001^{* * *}(0.00003)$ & $-0.0001^{* * *}(0.00003)$ & $-0.0001^{* * *}(0.00003)$ & $-0.0001^{* * *}(0.00005)$ & $-0.0009^{* * *}(0.00003)$ & $-0.0002^{* * *}(0.00004)$ \\
\hline MK & $-0.505^{* * *}(0.157)$ & $-0.464^{* * *}(0.143)$ & $-0.479^{* * *}(0.132)$ & $-0.259(0.206)$ & $-0.210(0.171)$ & $-0.214(0.248)$ \\
\hline $\mathrm{MK}^{2}$ & $0.319^{* *}(0.141)$ & $0.299 * *(0.126)$ & $0.313^{* *}(0.125)$ & $0.018(0.199)$ & $-0.006(0.166)$ & $-0.003(0.235)$ \\
\hline YEAR_FOND & $0.00007^{* *}(0.00002)$ & $0.00006^{* *}(0.00003)$ & $0.00005 *(0.00003)$ & $0.00006(0.00005)$ & $0.00006(0.00004)$ & $0.00005(0.00005)$ \\
\hline WOMEN & $4.62 \mathrm{e}-07(1.17 \mathrm{e}-06)$ & $-4.25 \mathrm{e}-08(1.23 \mathrm{e}-06)$ & $-9.40 \mathrm{e}-08(1.06 \mathrm{e}-06)$ & $-3.57 \mathrm{e}-06^{* *}(1.53 \mathrm{e}-06)$ & $-3.96 \mathrm{e}-06^{* * *}(1.37 \mathrm{e}-06)$ & $-4.25 \mathrm{e}-06^{* *}(1.32 \mathrm{e}-06)$ \\
\hline GDP & $-9.49 \mathrm{e}-07^{* * *}(2.32 \mathrm{e}-07)$ & & & $-1.06 \mathrm{e}-06^{*}(6.35 \mathrm{e}-07)$ & & \\
\hline FD_1 & & $-0.0007^{* * *}(0.0002)$ & & & $-0.0009^{* * *}(0.0003)$ & \\
\hline FD_2 & & & $-0.001^{* * *}(0.0004)$ & & & $-0.001(0.0008)$ \\
\hline NORTHERN & $-0.010(0.024)$ & $-0.016(0.023)$ & $-0.014(0.022)$ & $-0.011(0.048)$ & $-0.015(0.048)$ & $-0.017(0.036)$ \\
\hline CENTRAL & $-0.038(0.026)$ & $-0.042 *(0.024)$ & $-0.040^{* *}(0.018)$ & $-0.072(0.044)$ & $-0.073^{*}(0.041)$ & $-0.075^{*}(0.043)$ \\
\hline $\mathrm{T} 2$ & $-0.020(0.022)$ & $-0.019(0.019)$ & $-0.019(0.020)$ & $-0.002(0.032)$ & $-0.001(0.028)$ & $-0.001(0.031)$ \\
\hline T3 & $-0.107^{* * *}(0.025)$ & $-0.108^{* * *}(0.022)$ & $-0.107^{* * *}(0.022)$ & $-0.065^{* *}(0.034)$ & $-0.066^{*}(0.036)$ & $-0.065^{* *}(0.028)$ \\
\hline $\mathrm{T} 4$ & $-0.156^{* * *}(0.025)$ & $-0.157^{* * *}(0.020)$ & $-0.155^{* * *}(0.023)$ & $-0.100^{* * *}(0.035)$ & $-0.100^{* * *}(0.032)$ & $-0.099^{* * *}(0.030)$ \\
\hline CONST & $0.449^{* * *}(0.070)$ & $0.449^{* * *}(0.085)$ & $0.481^{* * *}(0.076)$ & $0.359^{* * *}(0.127)$ & $0.348^{* * *}(0.108)$ & $0.384^{* * *}(0.121)$ \\
\hline
\end{tabular}

Table reports coefficients and standard error (in parentheses); ${ }^{* * *},{ }^{* *},{ }^{*}$ : statistically significant al $1 \%, 5 \%$ and $10 \%$ respectively.

Columns (1), (2) and (3) are associated with bootstrapped university efficiency scores in the first stage (Double-boot DEA procedure).

Columns (4), (5) and (6) are associated with not bootstrapped university efficiency scores in the first stage (Two-stage DEA procedure).

Table 9

DEA truncated bootstrapped second stage regression using quartile university efficiency scores.

\begin{tabular}{|c|c|c|c|c|c|c|c|c|c|}
\hline \multirow[b]{3}{*}{ Variables } & \multicolumn{3}{|c|}{ Min-Max Truncation - UB $=0.64 \& \mathrm{LB}=0.04$} & \multicolumn{3}{|c|}{ Min-Max Truncation - UB $=0.64 \& \mathrm{LB}=0.04$} & \multicolumn{3}{|c|}{ Min-Max Truncation - UB $=0.64 \& \mathrm{LB}=0.04$} \\
\hline & \multicolumn{3}{|c|}{ Without the 1st quartile } & \multicolumn{3}{|c|}{ Without the 4 th quartile } & \multicolumn{3}{|c|}{ Without the 1 st and the 4 th quartiles } \\
\hline & $(1)$ & $(2)$ & $(3)$ & (4) & (5) & (6) & $(7)$ & (8) & (9) \\
\hline MED & $\begin{array}{l}0.059^{* * *} \\
(0.020)\end{array}$ & $\begin{array}{l}0.064^{* * *} \\
(0.021)\end{array}$ & $0.063^{* *}(0.024)$ & $0.070^{* *}(0.028)$ & $0.077^{* * *}(0.028)$ & $0.076^{* * *}(0.028)$ & $0.078^{* * *}(0.027)$ & $\begin{array}{l}0.085^{* * *} \\
(0.030)\end{array}$ & $\begin{array}{l}0.083^{* *} \\
(0.035)\end{array}$ \\
\hline FPS & $\begin{array}{l}-0.0001^{* * *} \\
(0.00004)\end{array}$ & $\begin{array}{l}-0.0001^{* * *} \\
(0.00003)\end{array}$ & $\begin{array}{l}-0.0001^{* * *} \\
(0.00003)\end{array}$ & $\begin{array}{l}-0.00009^{*} \\
(0.00005)\end{array}$ & $\begin{array}{l}-0.0008^{* *} \\
(0.00004)\end{array}$ & $\begin{array}{l}-0.0001^{*} \\
(0.00005)\end{array}$ & $\begin{array}{l}-0.0001^{* *} \\
(0.00005)\end{array}$ & $\begin{array}{l}-0.0001^{* * *} \\
(0.00004)\end{array}$ & $\begin{array}{l}-0.0001^{*} \\
(0.00007)\end{array}$ \\
\hline MK & $\begin{array}{l}-0.450^{* *} \\
(0.176)\end{array}$ & $\begin{array}{l}-0.416^{* * * *} \\
(0.122)\end{array}$ & $\begin{array}{l}-0.429^{* * *} \\
(0.136)\end{array}$ & $-0.625^{* * *}(0.205)$ & $\begin{array}{l}-0.566^{* *} \\
(0.255)\end{array}$ & $\begin{array}{l}-0.584^{* * *} \\
(0.210)\end{array}$ & $-0.635^{* * *}(0.224)$ & $\begin{array}{l}-0.586^{* *} \\
(0.246)\end{array}$ & $\begin{array}{l}-0.605^{* *} \\
(0.259)\end{array}$ \\
\hline $\mathrm{MK}^{2}$ & $0.296^{*}(0.158)$ & $0.280^{* *}(0.112)$ & $0.291^{* *}(0.120)$ & $0.427^{* *}(0.181)$ & $0.398 *(0.238)$ & $0.413^{* *}(0.189)$ & $0.466^{* *}(0.196)$ & $0.443^{* *}(0.220)$ & $0.459^{*}(0.236)$ \\
\hline YEAR_FOND & $\begin{array}{l}0.00006^{*} \\
(0.00003)\end{array}$ & $\begin{array}{l}0.00006^{*} \\
(0.00003)\end{array}$ & $\begin{array}{l}0.00005^{*} \\
(0.00003)\end{array}$ & $\begin{array}{l}0.00007 \\
(0.00004)\end{array}$ & $\begin{array}{l}0.00007^{*} \\
(0.00004)\end{array}$ & $\begin{array}{l}0.00005 \\
(0.00004)\end{array}$ & $\begin{array}{l}0.00007 \\
(0.00005)\end{array}$ & $\begin{array}{l}0.00007 \\
(0.00005)\end{array}$ & $\begin{array}{l}0.00006 \\
(0.00006)\end{array}$ \\
\hline WOMEN & $\begin{array}{l}8.74 \mathrm{e}-07(1.32 \mathrm{e}- \\
06)\end{array}$ & $\begin{array}{l}5.05 e-07 \\
(8.63 e-07)\end{array}$ & $\begin{array}{l}4.43 e-07 \\
(1.08 e-06)\end{array}$ & $\begin{array}{l}-2.52 \mathrm{e}-07 \\
(1.93 \mathrm{e}-06)\end{array}$ & $\begin{array}{l}-9.50 \mathrm{e}-07 \\
(2.05 \mathrm{e}-06)\end{array}$ & $\begin{array}{l}-1.05 \mathrm{e}-06 \\
(1.91 \mathrm{e}-06)\end{array}$ & $\begin{array}{l}7.48 \mathrm{e}-07(1.80 \mathrm{e}- \\
06)\end{array}$ & $\begin{array}{l}2.34 \mathrm{e}-07 \\
(1.72 \mathrm{e}-06)\end{array}$ & $\begin{array}{l}9.67 e-08 \\
(1.57 e-06)\end{array}$ \\
\hline GDP & $\begin{array}{l}-7.97 \mathrm{e}-07^{* * *} \\
(2.26 \mathrm{e}-07)\end{array}$ & & & $\begin{array}{l}-1.41 \mathrm{e}-06^{* * *} \\
(4.87 \mathrm{e}-07)\end{array}$ & & & $\begin{array}{l}-1.22 \mathrm{e}-06^{* * *} \\
(5.51 \mathrm{e}-07)\end{array}$ & & \\
\hline FD_1 & & $\begin{array}{l}-0.0006^{* * *} \\
(0.0002)\end{array}$ & & & $\begin{array}{l}-0.001^{* * *} \\
(0.0003)\end{array}$ & & & $\begin{array}{l}-0.001^{* *} \\
(0.0004)\end{array}$ & \\
\hline FD_2 & & & $\begin{array}{l}-0.001^{* *} \\
(0.0004)\end{array}$ & & & $\begin{array}{l}-0.001^{* *} \\
(0.0008)\end{array}$ & & & $\begin{array}{l}-0.001^{* *} \\
(0.0008)\end{array}$ \\
\hline NORTHERN & $0.004(0.025)$ & $-0.001(0.022)$ & $0.001(0.023)$ & $-0.036(0.041)$ & $-0.043(0.036)$ & $-0.045(0.043)$ & $-0.013(0.040)$ & $-0.020(0.034)$ & $\begin{array}{l}-0.021 \\
(0.039)\end{array}$ \\
\hline CENTRAL & $-0.021(0.023)$ & $-0.024(0.021)$ & $-0.022(0.021)$ & $-0.057(0.035)$ & $-0.062 *(0.032)$ & $-0.062 *(0.033)$ & $-0.034(0.030)$ & $-0.038(0.031)$ & $\begin{array}{l}-0.038 \\
(0.032)\end{array}$ \\
\hline $\mathrm{T} 2$ & $0.001(0.024)$ & $0.002(0.025)$ & $0.003(0.026)$ & $-0.034(0.024)$ & $-0.033(0.023)$ & $-0.033(0.022)$ & $-0.009(0.027)$ & $-0.009(0.031)$ & $\begin{array}{l}-0.008 \\
(0.030)\end{array}$ \\
\hline T3 & $-0.084^{* * *}(0.021)$ & $\begin{array}{l}-0.084^{* * *} \\
(0.026)\end{array}$ & $\begin{array}{l}-0.083^{* * *} \\
(0.021)\end{array}$ & $-0.124^{* * *}(0.029)$ & $\begin{array}{l}-0.125^{* * *} \\
(0.028)\end{array}$ & $\begin{array}{l}-0.124^{* * *} \\
(0.029)\end{array}$ & $-0.100^{* * *}(0.032)$ & $\begin{array}{l}-0.101^{* * *} \\
(0.038)\end{array}$ & $\begin{array}{l}-0.100^{* *} \\
(0.043)\end{array}$ \\
\hline $\mathrm{T} 4$ & $-0.133^{* * *}(0.020)$ & $\begin{array}{l}-0.134^{* * *} \\
(0.028)\end{array}$ & $\begin{array}{l}-0.132^{* * *} \\
(0.027)\end{array}$ & $-0.180^{* * *}(0.031)$ & $\begin{array}{l}-0.182^{* * *} \\
(0.026)\end{array}$ & $\begin{array}{l}-0.180^{* * *} \\
(0.033)\end{array}$ & $-0.162^{* * *}(0.034)$ & $\begin{array}{l}-0.164^{* * *} \\
(0.039)\end{array}$ & $\begin{array}{l}-0.162^{* * *} \\
(0.054)\end{array}$ \\
\hline CONST & $0.407^{* * *}(0.094)$ & $\begin{array}{l}0.401^{* * *} \\
(0.105)\end{array}$ & $\begin{array}{l}0.434^{* * *} \\
(0.073)\end{array}$ & $0.463^{* * *}(0.110)$ & $0.465^{* * *}(0.108)$ & $0.497^{* * *}(0.080)$ & $0.426^{* * *}(0.124)$ & $\begin{array}{l}0.421^{* * *} \\
(0.132)\end{array}$ & $\begin{array}{l}0.461^{* * *} \\
(0.124)\end{array}$ \\
\hline
\end{tabular}

Table reports coefficients and standard error (in parentheses); ${ }^{* * *},{ }^{* *},{ }^{*}$ : statistically significant al $1 \%, 5 \%$ and $10 \%$ respectively.

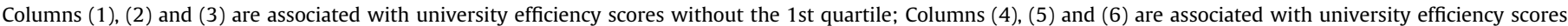
without the 4th quartile; Columns (7), (8) and (9) are associated with university efficiency scores without the 1st and the 4th quartiles.

All estimates are associated with bootstrapped university efficiency scores in the first stage (Double-boot DEA procedure). 
Table 10

SFA directional output distance - Variables affecting inefficiency - Using a Cobb-Douglas production function.

\begin{tabular}{|c|c|c|c|c|c|c|}
\hline Variables & Model A & Model B & Model C & Model A1 & Model B1 & Model C1 \\
\hline MED & $0.042(0.034)$ & $0.040(0.036)$ & $0.038(0.035)$ & $0.051(0.033)$ & $0.049(0.033)$ & $0.054(0.033)$ \\
\hline FPS & $-0.0004^{* * *}(0.00007)$ & $-0.0003^{* * *}(0.00008)$ & $-0.0004^{* * *}(0.00007)$ & $-0.0004^{* * *}(0.00007)$ & $-0.0004^{* * *}(0.00007)$ & $-0.0004^{* * *}(0.00007)$ \\
\hline MK & $-0.381^{* *}(0.096)$ & $-0.238^{* *}(0.113)$ & $-0.344^{* * *}(0.097)$ & $-0.276^{* *}(0.137)$ & $-0.318^{* * *}(0.121)$ & $-0.316^{* *}(0.125)$ \\
\hline $\mathrm{MK}^{2}$ & $0.758^{*}(0.228)$ & $0.646^{* *}(0.260)$ & $0.719^{* * *}(0.227)$ & $0.617^{* *}(0.275)$ & $0.663^{* *}(0.266)$ & $0.669 * *(0.266)$ \\
\hline YEAR_FOND & $0.0001^{* * *}(0.00006)$ & $0.0001^{* *}(0.00007)$ & $0.0001^{* * *}(0.00006)$ & $0.0001^{* *}(0.00006)$ & $0.0001^{* *}(0.00006)$ & $0.0005^{* *}(0.00006)$ \\
\hline WOMEN & $-8.94 \mathrm{e}-06^{* * *}(2.88 \mathrm{e}-06)$ & $-9.80 \mathrm{e}-06^{* * *}(3.16 \mathrm{e}-06)$ & $-8.98 \mathrm{e}-06^{* * *}(2.85 \mathrm{e}-06)$ & $-0.00001^{* * *}(3.02 \mathrm{e}-06)$ & $-0.00001^{* * *}(2.86 \mathrm{e}-06)$ & $-0.00001^{* * *}(2.91 \mathrm{e}-06)$ \\
\hline GDP & $-8.19 \mathrm{e}-07(6.12 \mathrm{e}-07)$ & & & $0.00003(0.00002)$ & & \\
\hline FD_1 & & $-0.004^{* *}(0.001)$ & & & $-0.0003(0.0004)$ & \\
\hline FD_2 & & & $-0.001^{* * *}(0.0009)$ & & & $0.001(0.001)$ \\
\hline NORTHERN & $-0.069(0.050)$ & $-0.075(0.056)$ & $-0.072(0.049)$ & $-0.109 *(0.060)$ & $-0.117(0.071)$ & $-0.127(0.084)$ \\
\hline CENTRAL & $-0.023^{* * *}(0.046)$ & $-0.299^{* * *}(0.053)$ & $-0.227^{* * *}(0.047)$ & $-0.267^{* * *}(0.044)$ & $-0.285^{* * *}(0.055)$ & $-0.313^{* * *}(0.083)$ \\
\hline $\mathrm{T} 2$ & $0.068(0.098)$ & $0.020(0.069)$ & $0.070(0.101)$ & $0.086(0.101)$ & $0.084(0.101)$ & $0.073(0.099)$ \\
\hline T3 & $-0.042(0.091)$ & $-0.055(0.070)$ & $-0.041(0.094)$ & $-0.040(0.091)$ & $-0.041(0.092)$ & $-0.046(0.089)$ \\
\hline $\mathrm{T} 4$ & $-0.092(0.095)$ & $-0.070(0.072)$ & $-0.093(0.097)$ & $-0.090^{* * *}(0.095)$ & $-0.090(0.096)$ & $-0.090(0.094)$ \\
\hline CONST & $0.195(0.171)$ & $0.017(0.166)$ & $0.176(0.174)$ & $0.270(0.186)$ & $0.263(0.192)$ & $0.267(0.197)$ \\
\hline
\end{tabular}

Table reports coefficients and standard error (in parentheses); ${ }^{* * *},{ }^{* *},{ }^{*}$ : statistically significant al $1 \%, 5 \%$ and $10 \%$ respectively.

In Models A, B and C, the variables GDP, FD_1 and FD_2 are measured at province level.

In Models A1, B1 and C1, the variables GDP, FD_1 and FD_2 are measured at regional level.

Table 11

SFA directional output distance - Variables affecting inefficiency - Using a Translog production function.

\begin{tabular}{|c|c|c|c|c|c|c|}
\hline Variables & Model A & Model B & Model C & Model A1 & Model B1 & Model C1 \\
\hline MED & $0.098^{* *}(0.048)$ & $0.098^{* *}(0.049)$ & $0.104^{* *}(0.048)$ & $0.053(0.046)$ & $0.072(0.044)$ & $0.063(0.043)$ \\
\hline FPS & $-0.0003^{* * *}(0.0001)$ & $-0.0003^{* * *}(0.0001)$ & $-0.0003^{* * *}(0.0001)$ & $-0.0001 *(0.0001)$ & $-0.0002 *(0.0001)$ & $-0.0001 *(0.0001)$ \\
\hline MK & $-0.349(0.225)$ & $-0.439 * *(0.193)$ & $-0.434^{* *}(0.199)$ & $-0.518^{* * *}(0.134)$ & $-0.350^{* *}(0.146)$ & $-0.339^{* *}(0.144)$ \\
\hline $\mathrm{MK}^{2}$ & $0.627(0.456)$ & $0.758^{*}(0.430)$ & $0.762 *(0.429)$ & $0.948^{* * *}(0.308)$ & $0.814^{* *}(0.330)$ & $0.777^{* *}(0.325)$ \\
\hline YEAR_FOND & $0.0001^{*}(0.0001)$ & $0.0002 *(0.0001)$ & $0.0001 *(0.0001)$ & $0.0002^{* * *}(0.0001)$ & $0.0002^{* *}(0.0001)$ & $0.0002^{* * *}(0.00009)$ \\
\hline WOMEN & $-0.00003^{* * *}(0.000005)$ & $-0.00002^{* * *}(0.000005)$ & $-0.00003^{* * *}(0.000005)$ & $-0.00003^{* * *}(0.000006)$ & $-0.00003^{* * *}(0.000006)$ & $-0.00003^{* * *}(0.000006)$ \\
\hline GDP & $0.00004(0.00005)$ & & & $-0.000006^{* * *}(0.000002)$ & & \\
\hline FD_1 & & $0.0004(0.0008)$ & & & $-0.006^{* * *}(0.001)$ & \\
\hline FD_2 & & & $0.001(0.002)$ & & & $-0.0110^{* * *}(0.002)$ \\
\hline NORTHERN & $-0.303^{* * *}(0.108)$ & $-0.292^{* *}(0.127)$ & $-0.290^{* *}(0.126)$ & $-0.256^{* * *}(0.070)$ & $-0.279^{* * *}(0.071)$ & $-0.301^{* * *}(0.071)$ \\
\hline CENTRAL & $-0.368 * * *(0.073)$ & $-0.383^{* * *}(0.093)$ & $-0.407^{* * *}(0.129)$ & $-0.370^{* * *}(0.061)$ & $-0.377^{* * *}(0.062)$ & $-0.399 * * *(0.060)$ \\
\hline $\mathrm{T} 2$ & $-0.115^{*}(0.065)$ & $-0.120 *(0.065)$ & $-0.128 *(0.065)$ & $-0.135^{* *}(0.058)$ & $-0.143^{* *}(0.058)$ & $-0.138^{* *}(0.057)$ \\
\hline T3 & $-0.249^{* * *}(0.079)$ & $-0.253^{* * *}(0.079)$ & $-0.262^{* * *}(0.080)$ & $-0.254^{* * *}(0.067)$ & $-0.278^{* * *}(0.068)$ & $-0.261^{* * *}(0.066)$ \\
\hline $\mathrm{T} 4$ & $-0.292^{* * *}(0.080)$ & $-0.297^{* * *}(0.080)$ & $-0.304^{* * *}(0.081)$ & $-0.286^{* * *}(0.071)$ & $-0.307^{* * *}(0.071)$ & $-0.288^{* * *}(0.069)$ \\
\hline CONST & $0.410(0.265)$ & $0.374(0.268)$ & $0.395(0.288)$ & $0.427^{*}(0.231)$ & $0.457^{* *}(0.229)$ & $0.520^{* *}(0.228)$ \\
\hline
\end{tabular}

Table reports coefficients and standard error (in parentheses); ${ }^{* * *},{ }^{* *},{ }^{*}$ : statistically significant al $1 \%, 5 \%$ and $10 \%$ respectively.

In Models A, B and C, the variables GDP, FD_1 and FD_2 are measured at province level.

In Models A1, B1 and C1, the variables GDP, FD_1 and FD_2 are measured at regional level.

\section{References}

[1] Donina D, Meoli M, Paleari S. Higher education reform in Italy: tightening regulation instead of steering at a distance. High Educ Policy 2015;28(2): 215-34.

[2] Olivares M, Wetzel H. Competing in the higher education market: empirical evidence for economies of scale and scope in German higher education institutions. CESifo Econ Stud 2014:60(4):653-80.

[3] OECD. Tertiary education for the knowledge society. Paris: OECD Publishing; 2008. Available at: www.oecd.org/edu/tertiary/review.

[4] Aigner D, Lovell K, Schmidt P. Formulation and estimation of stochastic frontier production function models. J Econ 1977;6:21-37.

[5] Charnes A, Cooper WW, Rhodes E. Measuring the efficiency of decision making units. Eur J Oper Res 1978;2:429-44.

[6] Lewin AY, Lovell CAK. Frontier analysis: parametric and nonparametric approaches. J Econ 1990;46:1-245.

[7] Johnes J. Efficiency measurement. In: Johnes G, Johnes J, editors. International handbook on the economics of education. Cheltenham: Edward Elgar Publishing; 2004. p. 613-742.

[8] Chakraborty K, Biswas B, Lewis WC. Measurement of technical efficiency in public education: a stochastic and non-stochastic production frontier approach. South Econ J 2001:67(4):889-905.

[9] Johnes G. The costs of multiproduct organizations and the heuristic evaluation of industrial structure. Socio Econ Plan Sci 1998;32(3):199-209.

[10] Johnes J. Efficiency and mergers in English higher education 1996/97 to 2008/ 9: parametric and non-parametric estimation of the multi-input multi-output distance function. Manch Sch 2014;82:465-87.

[11] Bates JM. Measuring predetermined socio-economic "inputs" when assessing the efficiency of educational outputs. Appl Econ 1997;29(1):85-93.

[12] Farsi M, Filippini MA. Benchmarking analysis of electricity distribution utilities in Switzerland. CEPE Working Paper No. 43. Zurich: Center for Energy
Policy and Economics, Swiss Federal Institute of Technology; 2005.

[13] Cullinane K, Wang TF, Song DW, Ji P. The technical efficiency of containe ports: comparing data envelopment analysis and stochastic frontier analysis. Transp Res Part A 2006;40:354-74.

[14] Cubbin J, Zamani H. A comparison of performance indicators for Training and Enterprise Councils in the UK. Ann Public Choice Coop Econ 1996;67(4): 603-32.

[15] Cooper WW, Tone K. Measures of inefficiency in data envelopment analysis and stochastic frontier estimation. Eur I Oper Res 1997:99:72-88.

[16] Gong BH, Sickles RC. Finite sample evidence on the performance of stochastic frontiers and data envelopment analysis using panel data. J Econ 1992;51: 259-84.

[17] Huguenin JM. Adjusting for the environment in DEA: a comparison of alternative models based on empirical data. Socio Econ Plan Sci 2015;52:41-54.

[18] Simar L, Wilson PW. Estimation and inference in two-stage, semi-parametric models of production processes. J Econ 2007;136(1):31-64.

[19] Wolszczak-Derlacz J, Parteka A. Efficiency of European public higher education institutions: a two-stage multi-country approach. Scientometrics 2011;89:887-917.

[20] Curi C, Daraio C, Llerena P. University technology transfer: how (in)efficient are French universities? Camb J Econ 2012;36:629-54.

[21] Cotte A. Estimating effectiveness of the control of violence and socioeconomic development in Colombia: an application of dynamic Data Envelopment Analysis and Data Panel Approach. Soc Indic Res 2012;105(3):343-66.

[22] Greene W. Reconsidering heterogeneity in panel data estimators of the stochastic frontier model. J Econ 2005;126(2):269-303.

[23] Wang HJ, Ho CW. Estimating fixed-effect panel stochastic frontier models by model transformation. J Econ 2010;157(2):286-96.

[24] Coelli T, Perelman S. Technical efficiency of European railways, a distance function approach. Appl Econ 2000;32:1967-76.

[25] Lovell CAK, Richardson S, Travers P, Wood LL. Resources and functionings: a 
new view of inequality in Australia. In: Eichhorn W, editor. Models and measurement of welfare and inequality. Berlin: Springer-Verlag; 1994. p. 787-807.

[26] Abbot M, Doucouliagos C. Competition and efficiency: overseas students and technical efficiency in Australian and New Zealand universities. Educ Econ 2009;17(1):31-57.

[27] Coelli TJ. On the econometric estimation of the distance function representation of a production technology. Working Paper, 2000/042. 2000.

[28] De Witte K, Hudrlikova L. What about excellence in teaching? A benevolent ranking of universities. Scientometrics 2013;96:337-64.

[29] Hazelkorn E. The impact of league tables and ranking systems on higher education decision making. High Educ Manag Policy 2007;19:2.

[30] Tofallis C. A different approach to university rankings. High Educ 2012;63(1): $1-18$.

[31] Clarke M. The impact of higher education rankings on student access, choice, and opportunity. High Educ Eur 2007;32(1):59-70.

[32] Eff EA, Klein CC, Kyle R. Identifying the best buys in U.S. higher education. Res High Educ 2012;53(8):860-87.

[33] Harvey L. Assaying improvement. In: Paper presented at the 30th EAIR Forum; 2008. Copenhagen, Denmark, 24-27 August.

[34] Agasisti T, Dal Bianco A. Reforming the university sector: effects on teaching efficiency. Evidence from Italy. High Educ 2009;57(4):477-98.

[35] Bonaccorsi A, Daraio C, Simar L. Advanced indicators of productivity of universities. An application of robust nonparametric methods to Italian data. Scientometrics 2006;66(2):389-410.

[36] Agasisti T. Performances and spending efficiency in Higher Education: a European comparison through non-parametric approaches. Educ Econ 2011;19(2):199-224.

[37] Wilson PW. FEAR 1.0: a software package for frontier efficiency analysis with R. Socio Econ Plan Sci 2008;42:247-54.

[38] Battese GE, Coelli TJ. A model for technical inefficiency effects in a stochastic frontier production function for panel data. Empir Econ 1995;20(2):325-32.

[39] Abbot M, Doucouliagos C. The efficiency of Australian universities: a data envelopment analysis. Econ Educ Rev 2003:22:89-97.

[40] Paul CJM, Johnston WE, Frengley GAG. Efficiency in New Zealand sheep and beef farming: the impacts of regulatory reform. Rev Econ Stat 2000;82(2): 325-37.

[41] Wang HJ, Schmidt P. One-step and two-step estimation of the effects of exogenous variables on technical efficiency levels. J Prod Anal 2002;18: $129-44$.

[42] Alvarez A, Amsler C, Orea L, Schmidt P. Interpreting and testing the scaling property in models where inefficiency depends on firm characteristics. J Prod Anal 2006;25:201-12.

[43] Cohn E, Cooper ST. Multi-product cost functions for universities: economies of scale and scope. In: International handbook on the economics of education, vol. 579; 2004.

[44] Agasisti T, Johnes G. Cost structure, efficiency and heterogeneity in US higher education: an empirical analysis. LUMS Working Paper 2009/013. 2009.

[45] Agasisti T, Barra C, Zotti R. Evaluating the efficiency of Italian public universities (2008-2011) in presence of (unobserved) heterogeneity. Socio Econ Plan Sci 2016:55:47-58.

[46] Laureti T. Modelling exogenous variables in human capital formation through a heteroscedastic stochastic frontier. Int Adv Econ Res 2008;14(1):76-89.

[47] Agasisti T, Haelermans C. Comparing efficiency of public universities among European countries: different incentives lead to different performances. High Educ Q 2016;70(1):81-104.

[48] Arulampalam W, Naylor R, Robin A, Smith JP. Hazard model of the probability of medical school drop-out in the UK. J R Stat Soc Ser A 2004:167(1):157-78.

[49] Boero G, Mcnight A, Naylor R, Smith J. Graduates and graduate labour markets in the UK and Italy. Lav Relaz. Ind 2001;2:131-72.

[50] Lassibille G. Student progress in higher education: what we have learned from large-scale studies. Open Educ J 2011;4:1-8.

[51] Smith J, Naylor R. Determinants of degree performance in UK universities: a statistical analysis of the 1993 student cohort. Oxf Bull Econ Stat 2001;63: 29-60.

[52] Desjardins SL, Ahlburg DA, Mccall BP. A temporal investigation of factors related to timely degree completion. J High Educ 2002;73(5):555-81.

[53] Catalano G, Mori A, Silvestri P, Todeschini P. Chi paga l'istruzione universitaria? Dall'esperienza europea una nuova politica di sostegno agli studenti in Italia. Milano: Franco Angeli; 1993.

[54] Madden G, Savage S, Kemp S. Measuring public sector efficiency: a study of Economics departments at Australian universities. Educ Econ 1997;5(2): 153-67.

[55] Worthington A, Lee BL. Efficiency, technology and productivity change in Australian universities, 1998-2003. Econ Educ Rev 2008;27:285-98.

[56] Eckles JE. Evaluating the efficiency of top Liberal Arts colleges. Res High Educ 2010;51(3):266-93.

[57] Johnes J. Performance assessment in higher education in Britain. Eur J Oper Res 1996;89:18-33.

[58] Johnes J. Measuring teaching efficiency in higher education: an application of data development analysis to economics graduates from UK Universities 1993. Eur J Oper Res 2006;174(1):443-56.

[59] De Groot H, McMahon WW, Volkwein JF. The cost structure of American research universities. Rev Econ Stat 1991;73(3):424-31.

[60] Athanassopoulos AD, Shale E. Assessing the comparative efficiency of higher education institutions in the UK by means of data envelopment analysis. Educ Econ 1997;5(2):117-34.

[61] Halkos G, Tzeremes NG, Kourtzidis SA. Measuring public owned university departments' efficiency: a bootstrapped DEA approach. J Econ Econ 2012;55(2):1-24.

[62] Johnes G, Johnes J. Measuring the research performance of UK economics departments: an application of data envelopment analysis. Oxf Econ Pap 1993; $45: 332-47$.

[63] Johnes J, Yu L. Measuring the research performance of Chinese higher education institutions using data envelopment analysis. China Econ Rev 2008;19(4):679-96.

[64] Tyagi P, Yadav SP, Singh SP. Relative performance of academic departments using DEA with sensitivity analysis. Eval Program Plan 2009;32:168-77.

[65] Zhang L, Bao W, Sun L. Resources and research production in higher education: a longitudinal analysis of Chinese universities, 2000-2010. Res High Educ 2016. http://dx.doi.org/10.1007/s11162-016-9410-6.

[66] Agasisti T, Johnes G. Beyond frontiers: comparing the efficiency of higher education decision-making units across more than one country. Educ Econ 2009a;17(1):59-79.

[67] Agasisti T, Johnes G. Heterogeneity and the evaluation of efficiency: the case of Italian universities. Appl Econ 2010;42(11):1365-75.

[68] Agasisti T, Catalano G, Landoni P, Verganti R. Evaluating the performance of academic departments: an analysis of research related output efficiency. Res Eval 2012;21(1):2-14.

[69] Kao C, Hung HT. Efficiency analysis of university departments: an empirical study. Omega 2008;36:653-64.

[70] Cave M, Hanney S, Kogan M. The use of performance indicators in higher education. A critical analysis of developing practices. London: Jessica Kingsley; 1991.

[71] Tomkins C, Green R. An experiment in the use of data envelopment analysis for evaluating the efficiency of UK university departments of accounting. Financ Account Manag 1988;4:147-64.

[72] Hashimoto A, Haneda S. Measuring the change in R\&D efficiency of the Japanese pharmaceutical industry. Res Policy 2008;37:1829-36.

[73] Emrouznejad A, Thanassoulis E. A mathematical model for dynamic efficiency using data envelopment analysis. Appl Math Comput 2005;160:363-78.

[74] Kempkes G, Pohl C. The efficiency of German universities-some evidence from nonparametric and parametric methods. Appl Econ 2010;42(16): 2063-79.

[75] Agasisti T. Market forces and competition in university systems: theoretical reflections and empirical evidence from Italy. Int Rev Appl Econ 2009;23(4): $463-83$.

[76] Titus MA, Pusser B. States' potential enrollment of adult students: a Stochastic Frontier Analysis. Res High Educ 2011;52(6):555-71.

[77] Brewer D, Gates SM, Goldman CA. In pursuit of prestige: strategy and competition in US higher education. New Brunswick, NJ: Transaction Press; 2002.

[78] Dill DD. Allowing the market to rule: the case of United States. High Educ Q 2003;57(2):136-57.

[79] Oliviera MA, Santos C. Assessing school efficiency in Portugal using FDH and bootstrapping. Appl Econ 2005;37:957-68.

[80] Bonaccorsi A, Daraio C. Exploring size and agglomeration effects on public research productivity. Scientometric 2005;63(1):87-120.

[81] Thursby JG, Kemp S. Growth and productive efficiency of university intellectual property licensing. Res Policy 2002:31:109-24.

[82] Anderson TR, Daim TU, Lavoie FF. Measuring the efficiency of university technology transfer. Technovation 2007;27:306-18.

[83] Chapple W, Lockett A, Siegel DS, Wright M. Assessing the relative performance of university technology transfer office in UK: parametric and nonparametric evidence. Res Policy 2005;34(3):369-84.

[84] Agasisti T, Wolszczak-Derlacz J. Exploring universities' efficiency differentials between countries in a multi-year perspective: an application of bootstrap DEA and Malmquist index to Italy and Poland, 2001-2011. IRLE Working Paper \#113/14. 2014.

[85] Ordine P, Lupi C. Family income and students' mobility. G degli Econ 2009;68(1):1-23.

[86] Rossi F. Increased competition and diversity in higher education: an empirical analysis of the Italian university system. High Educ Policy 2009;22(4): 389-413.

[87] Maietta OW. Determinants of university-firm R\&D collaboration and its impact on innovation: a perspective from a low-tech industry. Res Policy 2015;44(7):1341-59.

[88] Viesti G. Università in declino, Un'indagine sugli atenei da Nord a Sud. Donzelli. 2016.

[89] De Witte K, Lopez-Torres L. Efficiency in education: a review of literature and a way forward. J Oper Res Soc 2015. http://dx.doi.org/10.1057/jors.2015.92.

[90] Carrington R, Coelli T, Rao DSP. The performance of Australian universities: conceptual issues and preliminary results. Econ Pap 2005;24:145-63.

[91] Frey BS, Rost K. Do rankings reflect research quality? J Appl Econ 2010;13(1): $1-38$.

[92] O'Donnell C, Coelli TA. Bayesian approach to imposing curvature on distance functions. J Econ 2005;126(2):493-523.

[93] Restrepo-Tobon DA, Kumbhakar SC. Profit efficiency of U.S. commercia banks: a decomposition. Documentos de Trabajo CIEF 010939. Universidad Eafit; 2013. 
Cristian Barra, is a post-doctoral researcher at University of Salerno, Department of Economics and Statistics. He achieved the master in Economics and Finance at the University of Naples (Department of Economics and Statistics) - ITALY - and the PhD in Economics of the Public Sector at the University of Salerno (Department of Economics and Statistics) - ITALY. His current research focuses on the efficiency analysis of financial institutions and higher education institutions, and on the financial development and economic growth.

Raffaele Lagravinese, is a researcher at University of Bari "Aldo Moro", Department of Economics and Mathematical methods. He achieved the PhD in Economics University of Bari "Aldo Moro" (Department of Economics) - ITALY. He has been visiting scholar at Land Economy Department - Cambridge (UK), Brunel Business School - London (UK) and visiting PhD at Economics Department - University of York. His current research focuses on urban and regional economics, health economics and economics of education with expertise in Quantitative Social Research and Qualitative Social Research.

Roberto Zotti, is a post-doctoral researcher at University of Salerno, Department of Economics and Statistics. He achieved the master in Public Economics at the University of York (Department of Economics and Related Studies) - UK - and the PhD in Economics of the Public Sector at the University of Salerno (Department of Economics and Statistics) - ITALY. His current research focuses on the analysis of the choices regarding higher education, the impact of education on the economic system and the efficiency of higher education institutions. 